\title{
Synthesis, Cyclic Voltammetric, Electrochemical, and Gravimetric Corrosion Inhibition Investigations of Schiff Base Derived from 5,5-Dimethyl-1,3-cyclohexanedione and 2-Aminophenol on Mild Steel in $1 \mathrm{M} \mathrm{HCl}$ and $0.5 \mathrm{M} \mathrm{H}_{2} \mathrm{SO}_{4}$
}

\author{
Ragi Kooliyat, ${ }^{1}$ Joby Thomas Kakkassery ${ }^{D},{ }^{1}$ Vinod P. Raphael, ${ }^{2}$ \\ Sini Varghese Cheruvathur, ${ }^{1}$ and Binsi M. Paulson ${ }^{1}$ \\ ${ }^{1}$ Department of Chemistry, St. Thomas' College (Autonomous), Thrissur, Kerala 680001, India \\ ${ }^{2}$ Department of Chemistry, Govt. Engineering College, Thrissur, Kerala 680009, India
}

Correspondence should be addressed to Joby Thomas Kakkassery; drjobythomask@gmail.com

Received 21 November 2018; Revised 27 March 2019; Accepted 1 April 2019; Published 2 May 2019

Academic Editor: Davood Nematollahi

Copyright (C) 2019 Ragi Kooliyat et al. This is an open access article distributed under the Creative Commons Attribution License, which permits unrestricted use, distribution, and reproduction in any medium, provided the original work is properly cited.

\begin{abstract}
Schiff base 2,2'-(5,5-dimethylcyclohexane-1,3-diylidene)bis(azan-1-yl-1-ylidene) diphenol (DmChDp) was synthesized and characterized using spectroscopic methods (IR, UV, NMR, and Mass) and cyclic voltammetric (CV) studies. The corrosion inhibition potency of $(\mathrm{DmChDp})$ on mild steel (MS) in $1 \mathrm{M} \mathrm{HCl}$ and $0.5 \mathrm{M} \mathrm{H}_{2} \mathrm{SO}_{4}$ was investigated. The corrosion monitoring techniques employed for this purpose are gravimetric and electrochemical methods (EIS and potentiodynamic polarization studies). The study reveals that the Schiff base, DmChDp, acts as excellent corrosion inhibitor on mild steel in $1 \mathrm{M} \mathrm{HCl}$. DmChDp obeys Langmuir adsorption isotherm both in $1 \mathrm{M} \mathrm{HCl}$ and $0.5 \mathrm{M} \mathrm{H}_{2} \mathrm{SO}_{4}$ on $\mathrm{MS}$. Polarization studies show that DmChDp behaves as a mixed type inhibitor in both media. Scanning electron microscopic analysis established the protective nature of DmChDp on mild steel surface. The impact of temperature on the corrosion of MS was also evaluated using gravimetric method.
\end{abstract}

\section{Introduction}

Mild steel is used very commonly in industries because of its good weldability due to low carbon content as well as optimum mechanical properties at a cheaper cost [14]. However they easily undergo acid attack and get corroded. Acid solutions are commonly used in industries for various cleaning processes [5-8]. Corrosion inhibition using inhibitors is a developing field in chemistry. There are different types of inhibitors used for preventing corrosion. They include both inorganic and organic inhibitors. The toxic nature of inorganic inhibitors such as chromates and nitrites makes them less useful [9]. Environmentally benign organic inhibitors containing $\mathrm{N}, \mathrm{S}$, and/or $\mathrm{O}$ in the conjugated systems replace such toxic inhibitors. They inhibit the corrosion by adsorbing on metal surface forming a protective layer and thereby retard dissolution of metal in aggressive solutions [10-13]. Corrosion scientists and industrialists are always in search of potential, nontoxic, economic, and water soluble inhibitors to fight against metallic corrosion. To the best of our knowledge, no investigations were reported on the corrosion inhibition capacities of Schiff base derived from 5,5-dimethyl-1,3-cyclohexanedione and 2-aminophenol. The present paper explores the corrosion inhibition capacity of 2,2'-(5,5-dimethylcyclohexane-1,3-diylidene)bis(azan1-yl-1-ylidene)diphenol (DmChDp) on mild steel in $1 \mathrm{M} \mathrm{HCl}$ and $0.5 \mathrm{M} \mathrm{H}_{2} \mathrm{SO}_{4}$ using gravimetric and electrochemical studies.

\section{Materials and Methods}

2.1. Synthesis and Characterization. Hot ethanolic solution of 5,5-dimethyl-1,3-cyclohexanedione $(0.01 \mathrm{~mol})$ was added dropwise to a stirred solution containing $0.02 \mathrm{~mol}$ of 2 aminophenol dissolved in ethanol. The mixture was refluxed for about 20 minutes and cooled. The brown coloured 
precipitate formed was filtered, washed with distilled water, and dried. Figures 1(a) and 1(b) show the molecular structure and optimized geometry of $\mathrm{DmChDp}$, respectively. Anal.calcd for $\mathrm{C}_{20} \mathrm{H}_{22} \mathrm{~N}_{2} \mathrm{O}_{2}$ : C, 74.53; H, 6.83; N, 8.69\%. Found. C, 73.91; H, 6.74; N, 8.52\%; IR (KBr): $v_{\mathrm{C}=\mathrm{N}} 1600 \mathrm{~cm}^{-1}$. ${ }^{1} \mathrm{Hnmr}: \delta_{\mathrm{OH}} 9.877, \delta_{\mathrm{NH}} 8.397 .{ }^{13} \mathrm{Cnmr}: \delta_{\mathrm{CH}=\mathrm{N}}$ 95.88. Mass: $\mathrm{M}^{+}$ peak m/z: 322 is absent, base peak $\left[\mathrm{C}_{14} \mathrm{H}_{18} \mathrm{NO}\right]^{+} \mathrm{m} / \mathrm{z}: 216 . \mathrm{m}$. p. $=180^{\circ} \mathrm{C}$.

2.2. Cyclic Voltammetry. The electrochemical nature of DmChDp was investigated using cyclic voltammetric studies. Ivium CompactStat-e electrochemical system was used for this study. Three electrode systems consisting of glassy carbon, $\mathrm{Ag}-\mathrm{AgCl}$, and platinum loop were used as working electrode, reference electrode, and counter electrode, respectively, in this study [14]. $3 \mathrm{ml}$ solution of $\mathrm{DmChDp}$ $(0.1 \mathrm{mM})$ in DMSO was taken in the electrolytic cell and 2 $\mathrm{ml}$ of supporting electrolyte (tetra butyl ammonium hexa fluoro phosphate) (0.1 M) was added. The solution was kept unstirred and the cyclic voltammogram was recorded in the potential range $1.0 \mathrm{~V}$ to $-2.0 \mathrm{~V}$ at a scan rate of $0.02-0.1 \mathrm{~V} / \mathrm{s}$.

2.3. Solutions. The aggressive solutions of $1 \mathrm{M} \mathrm{HCl}$ and $0.5 \mathrm{M}$ $\mathrm{H}_{2} \mathrm{SO}_{4}$ needed for the corrosion inhibition studies were prepared by diluting analytical grade acids (Merck) with deionized water. The inhibitor solutions were prepared in aggressive solutions having a range of concentration $0.2 \mathrm{mM}$ $1.0 \mathrm{mM}$.

2.4. Weight Loss Measurements. Mild steel (MS) coupons having size $1 \times 1 \times 0.96 \mathrm{~cm}$ were taken for weight loss studies. Before the experiment, coupons were abraded with various grades of SiC papers (100, 220, 400, 600, 800, 1000, 1500, and 2000), washed with acetone followed by distilled water, and dried. The area and thickness of each MS coupons were measured and weighed. It is then immersed in $50 \mathrm{ml}$ acid solutions at $28^{\circ} \mathrm{C}$ in hanging position with and without $\mathrm{DmChDp}$ using fishing lines. Weight loss of the metal coupons was recorded after $24 \mathrm{~h}$. The corrosion rate $(v)$ was found out using the following equation [15]:

$$
v=\frac{K W}{D S t}
$$

where $\mathrm{K}=87600, \mathrm{~W}, \mathrm{~S}, \mathrm{D}, \mathrm{t}$ denotes average weight loss of coupon $(\mathrm{g})$, total area of specimen $\left(\mathrm{cm}^{2}\right)$, density of mild steel $\left(\mathrm{g} \mathrm{cm}^{-3}\right)$, and period of contact of metal with acid solution (h), respectively. The percentage of inhibition potency was calculated using the following equation $[16,17]$ :

$$
\eta \%=\frac{v_{0}-v}{v_{0}} \times 100
$$

where $v_{0}$ and $v$ represent corrosion rate of specimens in contact with the acid medium without and with $\mathrm{DmChDp}$, respectively.

2.5. Electrochemical Impedance Spectroscopy (EIS). The impedance studies were executed using Ivium CompactState electrochemical system. Three electrode systems consisting of platinum electrode having $1 \mathrm{~cm}^{2}$ area as counter electrode, saturated calomel electrode (SCE) as the reference electrode, metal specimen with an exposed area of $1 \mathrm{~cm}^{2}$ as working electrode were used for the studies. $1 \mathrm{M} \mathrm{HCl}$ and $0.5 \mathrm{M}$ $\mathrm{H}_{2} \mathrm{SO}_{4}$ were used as electrolytic solutions. Before each measurement, the working area of metal specimen was made into contact with the electrolyte for about 30 minutes. EIS measurements were determined at constant potential (OCP) in the frequency range $1 \mathrm{KHz}-100 \mathrm{MHz}$ with amplitude of $10 \mathrm{mV}$ as excitation signal. The corrosion inhibition potency was determined using charge transfer resistance obtained from impedance plots by the following expression [18]:

$$
\eta(E I S) \%=\frac{\mathrm{Rct}-\mathrm{R}^{\prime} \mathrm{ct}}{\mathrm{Rct}} \times 100
$$

where $\mathrm{R}_{\mathrm{ct}}$ and $\mathrm{R}_{\mathrm{ct}}^{\prime}$ represent charge transfer resistance of working electrode in contact with the acid medium with and without $\mathrm{DmChDp}$, respectively.

2.6. Potentiodynamic Polarization. The change of electrode potential of MS specimen in the test solution was studied under open circuit conditions. Electrochemical polarization studies involve the analysis of anodic and cathodic potentiodynamic polarization curves of $\mathrm{MS}$ specimen in $1 \mathrm{M} \mathrm{HCl}$ and $0.5 \mathrm{M} \mathrm{H}_{2} \mathrm{SO}_{4}$ with and without DmChDp. Polarization studies were carried out by varying the potential of working electrode from -250 to $+250 \mathrm{mV}$ relative to the corrosion potential $\left(\mathrm{E}_{\mathrm{corr}}\right)$ at a scan rate of $1 \mathrm{mV} / \mathrm{sec}$. Corrosion current density $\left(\mathrm{I}_{\text {corr }}\right.$ ) was obtained by interpolating anodic and cathodic curves to the potential axis by which the percentage of inhibition potency $\left(\eta_{\mathrm{pol}} \%\right)$ was calculated using the following equation $[19,20]$ :

$$
\eta(p o l) \%=\frac{\text { Icorr }-\mathrm{I}^{\prime} \text { corr }}{\text { Icorr }} \times 100
$$

where $I_{\text {corr }}$ and I' corr denote the corrosion current densities of working electrode in contact with the acidic medium, without and with DmChDp.

2.7. Scanning Electron Microscopy. The surface morphology of mild steel specimens was determined using scanning electron microscope (JEOL Model JSM - 6390LV) after treatment with $1 \mathrm{M} \mathrm{HCl}$ or $0.5 \mathrm{M} \mathrm{H}_{2} \mathrm{SO}_{4}$ solutions with and without DmChDp for $24 \mathrm{~h}$.

\section{Results and Discussion}

3.1. Cyclic Voltammetric Study. The cyclic voltammogram of $\mathrm{DmChDp}$ was recorded in the potential range $1.0 \mathrm{~V} / \mathrm{s}$ to -2.0 $\mathrm{V} / \mathrm{s}$ at a scan rate of $0.10 \mathrm{~V} / \mathrm{s}$ (Figure $2(\mathrm{a})$ ). There are three cathodic peaks (A, B, and C) and three anodic peaks (D, E, and F) in the forward and reverse scan, respectively. The two cathodic peaks $\mathrm{A}$ and $\mathrm{B}$ observed at a potential of $0.376 \mathrm{~V}$ and $-0.188 \mathrm{~V}$, respectively, are due to the successive one electron reduction processes occurring at two azomethine moieties. The cathodic peak observed at a potential of $-1.098 \mathrm{~V}$ is 


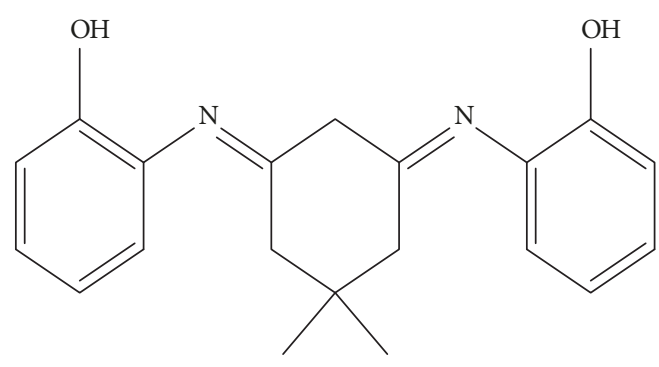

(a) Molecular structure of DmChDp

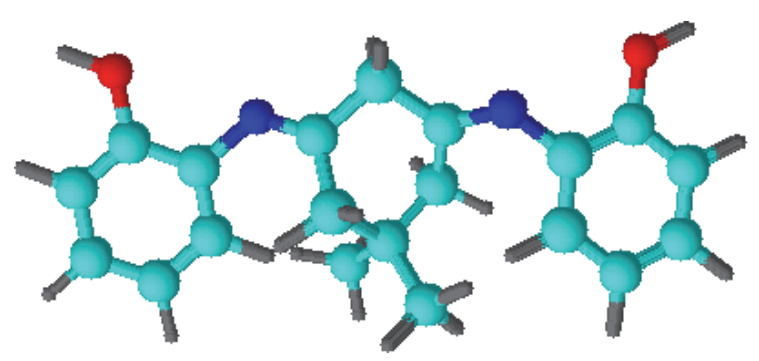

(b) Optimized geometry of DmChDp

Figure 1

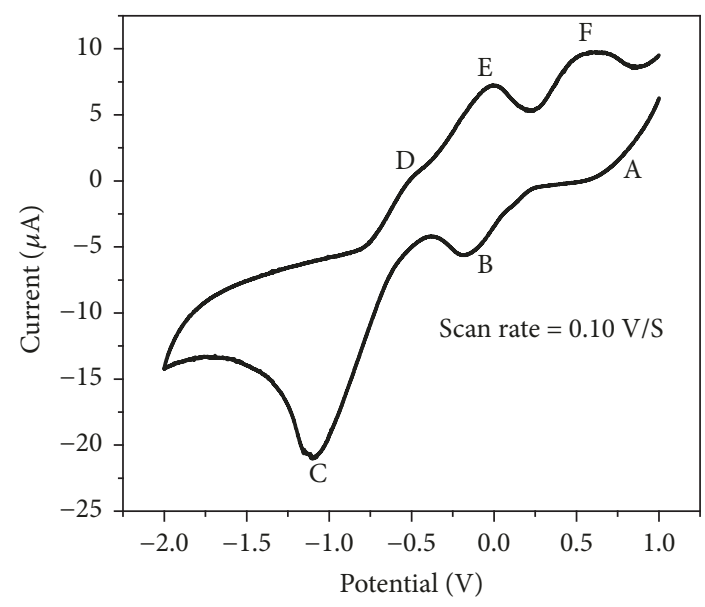

(a)

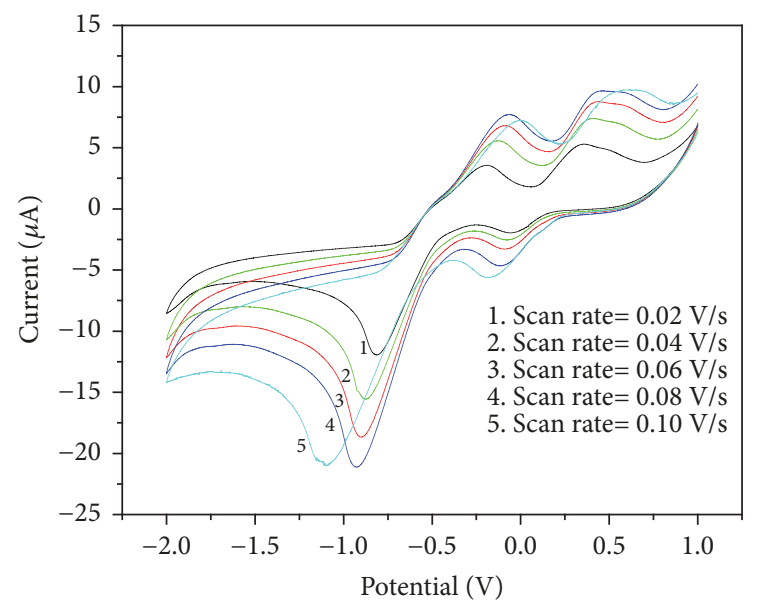

(b)

Figure 2: (a) Cyclic voltammogram of DmChDp at a scan rate of $0.10 \mathrm{~V} / \mathrm{s}$. (b) At scan rates 0.02-0.10 V/s.

considered due to two electron reduction occurring at two azomethine moieties since height of this peak is significantly higher than the other two cathodic peaks. The anodic peaks $\mathrm{D}$ and $\mathrm{E}$ observed at a potential of $-0.421 \mathrm{~V}$ and $-0.001 \mathrm{~V}$ are due to two successive one electron oxidation processes of the reduced form of $\mathrm{DmChDp}$. Though it is not clearly visible in voltammogram, the conversion of $\mathrm{E}$ to $\mathrm{F}$ takes place in two steps actually. The two stages having close oxidation potentials $(0.3610 \mathrm{~V}$ and $0.4790 \mathrm{~V})$ were more clearly visible in the voltammogram recorded at low scan rate $(0.02 \mathrm{~V} / \mathrm{s})$. There are no counter cathodic and anodic peaks observed in this redox processes. This indicates the irreversible nature of the electron transfer processes [21]. Cyclic voltammogram of $\mathrm{DmChDp}$ at different scan rates is given in Figure 2(b). The mechanism of redox process can be best viewed with the help of Figure 3.

\subsection{Weight Loss Measurements}

3.2.1. Impact of Inhibitor Concentration. The parameters of corrosion obtained by weight loss studies are shown in Table 1 . The data clearly shows that the rate of corrosion decreased with the concentration of DmChDp. Maximum inhibition efficiency of $94.01 \%$ was observed at $1 \mathrm{mM}$ concentration in $1 \mathrm{M} \mathrm{HCl}$ whereas it was $92.46 \%$ in $0.5 \mathrm{M} \mathrm{H}_{2} \mathrm{SO}_{4}$. This
TABLE 1: The rate of corrosion of MS and corrosion inhibition potency of $\mathrm{DmChDp}$ in $1 \mathrm{M} \mathrm{HCl}$ and $0.5 \mathrm{M} \mathrm{H}_{2} \mathrm{SO}_{4}$ at $28^{\circ} \mathrm{C}$ for 24 h.

\begin{tabular}{lcccc}
\hline & \multicolumn{2}{c}{$1 \mathrm{M} \mathrm{HCl}$} & \multicolumn{2}{c}{$0.5 \mathrm{M} \mathrm{H}_{2} \mathrm{SO}_{4}$} \\
$\begin{array}{l}\text { Conc. } \\
(\mathrm{mM})\end{array}$ & $\begin{array}{c}\text { Corrosion } \\
\text { rate }(v) \\
\left(\mathrm{mmy}^{-1}\right)\end{array}$ & $\begin{array}{c}\text { \%inhibition } \\
\text { potency } \\
\left(\eta_{\mathrm{w}} \%\right)\end{array}$ & $\begin{array}{c}\text { Corrosion } \\
\text { rate }(v) \\
\left(\mathrm{mmy}^{-1}\right)\end{array}$ & $\begin{array}{c}\text { \%inhibition } \\
\text { potency } \\
\left(\eta_{\mathrm{w}} \%\right)\end{array}$ \\
\hline 0 & 7.3 & - & 35.20 & - \\
0.2 & 1.2 & 83.47 & 19.80 & 43.73 \\
0.4 & 1.09 & 85.09 & 7.87 & 77.63 \\
0.6 & 0.52 & 92.83 & 7.49 & 78.70 \\
0.8 & 0.46 & 93.67 & 2.97 & 91.54 \\
1 & 0.43 & 94.01 & 2.65 & 92.46 \\
\hline
\end{tabular}

clearly indicates that $\mathrm{DmChDp}$ is acting as a good corrosion inhibitor for $\mathrm{MS}$ in $1 \mathrm{M} \mathrm{HCl}$ and $0.5 \mathrm{M} \mathrm{H}_{2} \mathrm{SO}_{4}$ according to gravimetric studies

3.2.2. Comparison between $\eta_{\mathrm{w}} \%$ of DmChDp with Its Parent Compounds. The comparison of corrosion inhibition potency of DmChDp with parent ketone, 5,5-dimethyl-1,3cyclohexanedione (Dm) and amine, 2-aminophenol (2AmP), 


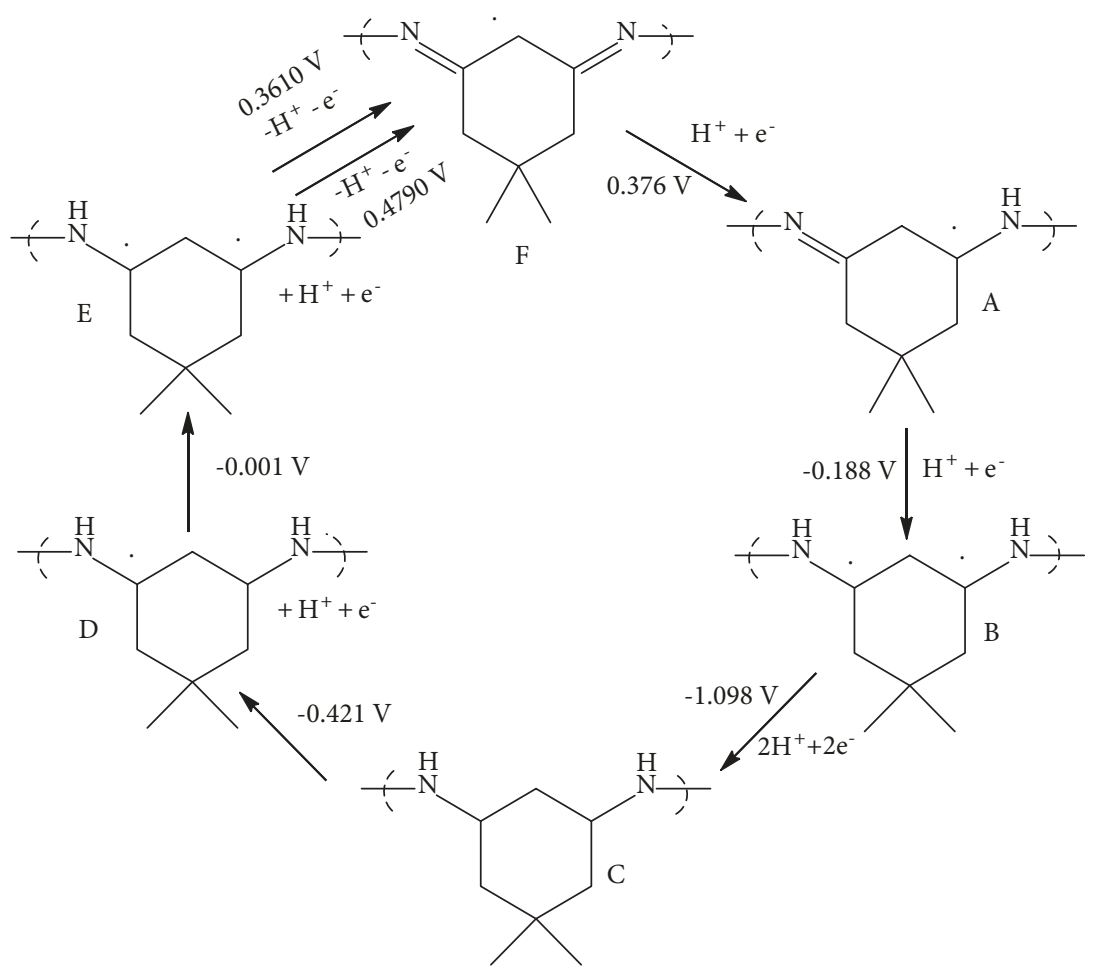

FIGURE 3: Redox mechanism occurring at azomethine moiety of DmChDp.

TABLE 2: The corrosion inhibition potency of parent ketone and amine of $\mathrm{DmChDp}$ on $\mathrm{MS}$ in $1 \mathrm{M} \mathrm{HCl}$ and $0.5 \mathrm{M} \mathrm{H}_{2} \mathrm{SO}_{4}$.

\begin{tabular}{lcccc}
\hline & \multicolumn{4}{c}{ \% inhibition potency $\left(\eta_{\mathrm{w}} \%\right)$} \\
Conc & \multicolumn{2}{c}{$1 \mathrm{M} \mathrm{HCl}$} & \multicolumn{2}{c}{$0.5 \mathrm{M} \mathrm{H}_{2} \mathrm{SO}_{4}$} \\
$(\mathrm{mM})$ & $\mathrm{Dm}$ & $2 \mathrm{AmP}$ & $\mathrm{Dm}$ & $2 \mathrm{AmP}$ \\
\hline 0.2 & -85.40 & -98.50 & 29.50 & 21.14 \\
0.6 & -70.67 & -67.76 & 38.68 & 25.22 \\
1 & -42.56 & -65.68 & 56.23 & 29.86 \\
\hline
\end{tabular}

was carried out by weight loss studies of mild steel in $1 \mathrm{M} \mathrm{HCl}$ and $0.5 \mathrm{M} \mathrm{H}_{2} \mathrm{SO}_{4}$ at $28^{\circ} \mathrm{C}$. The values of inhibition potency obtained are given in Table 2. The data indicates that the corrosion inhibition potency of $\mathrm{DmChDp}$ was very much higher than the corresponding parent ketone and amine in both acid media. This is due to the participation of electron rich azomethine $-\mathrm{C}=\mathrm{N}$ - group present in $\mathrm{DmChDp}$ in the corrosion inhibition process [22, 23].

3.2.3. Determination of Adsorption Isotherm. The adsorption isotherms are used to illustrate the corrosion inhibition mechanism of molecules [24]. Isotherms give information regarding the nature of interaction between metal and inhibitor. Langmuir, El-Awady, Frumkin, Temkin, Freundlich, and Flory-Huggins isotherms are the different adsorption isotherms considered for the study $[25,26]$. The most suitable isotherm was identified using correlation coefficient $\left(\mathrm{R}^{2}\right)$. The best one for the adsorption behaviour of
DmChDp on MS coupons in $1 \mathrm{M} \mathrm{HCl}$ and $0.5 \mathrm{M} \mathrm{H}_{2} \mathrm{SO}_{4}$ was Langmuir adsorption isotherm. The isotherm is expressed as

$$
\frac{C}{\theta}=\frac{1}{K}+C
$$

where $\theta$ is fractional surface coverage, $\mathrm{C}$ is concentration of the inhibitor, and $\mathrm{K}_{\mathrm{ads}}$ is adsorption equilibrium constant. The relation between adsorption equilibrium constant $\mathrm{K}_{\mathrm{ads}}$ and standard free energy of adsorption $\Delta G^{0}$ ads is given by $[27,28]$.

$$
\Delta \mathrm{G}_{\mathrm{ads}}^{0}=-\mathrm{RT} \ln \left(55.5 \mathrm{~K}_{\mathrm{ads}}\right)
$$

where 55.5 is the molar concentration of water, $\mathrm{R}$ and $\mathrm{T}$ represent universal gas constant and temperature in $\mathrm{K}$, respectively. The $\Delta \mathrm{G}^{0}$ ads value upto $-20 \mathrm{kJmol}^{-1}$ indicates that the interaction of charged molecule and charged metal surface is electrostatic in nature (physisorption) while if its value is more negative than $-40 \mathrm{kJmol}^{-1}$ indicates the presence of coordinate type bond between inhibitor molecules and metal surface (chemisorption) [29]. In the present investigation, DmChDp on MS in $1 \mathrm{M} \mathrm{HCl}$ and $0.5 \mathrm{M} \mathrm{H}_{2} \mathrm{SO}_{4}$ showed $\Delta \mathrm{G}^{0}$ ads -34.86 and $-30.37 \mathrm{kJmol}^{-1}$, respectively, implying that the adsorption behaviour of $\mathrm{DmChDp}$ involves both electrostatic and chemical interaction. Langmuir adsorption isotherms of DmChDp on $\mathrm{MS}$ coupon in $1 \mathrm{M} \mathrm{HCl}$ and $0.5 \mathrm{M} \mathrm{H}_{2} \mathrm{SO}_{4}$ at $28^{\circ} \mathrm{C}$ are shown in Figure 4 . The predicted mechanism of interaction of $\mathrm{DmChDp}$ on MS surface in acid can be viewed with the help of Figure 5. It may be assumed that DmChDp interact on the metal mainly through aromatic rings and azomethine groups. 


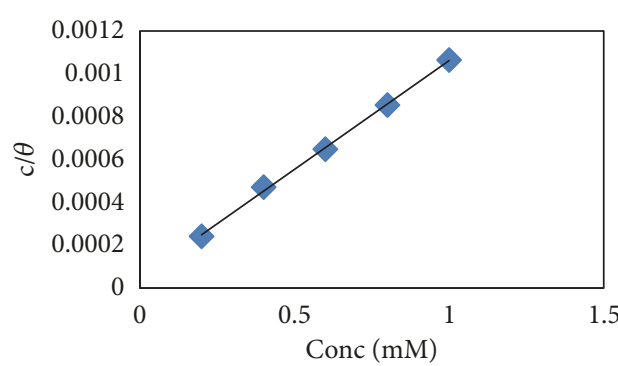

(a)

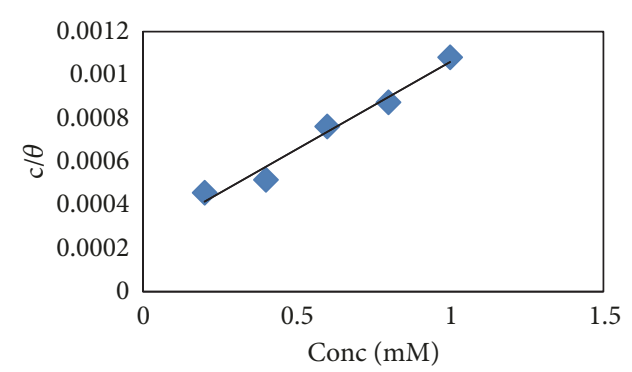

(b)

FIgURE 4: (a) Langmuir adsorption isotherm of $\mathrm{DmChDp}$ on $\mathrm{MS}$ in $1 \mathrm{M} \mathrm{HCl}$ at $28^{\circ} \mathrm{C}$. (b) Langmuir adsorption isotherm of $\mathrm{DmChDp}$ on $\mathrm{MS}$ in $0.5 \mathrm{M} \mathrm{H}_{2} \mathrm{SO}_{4}$ at $28^{\circ} \mathrm{C}$.

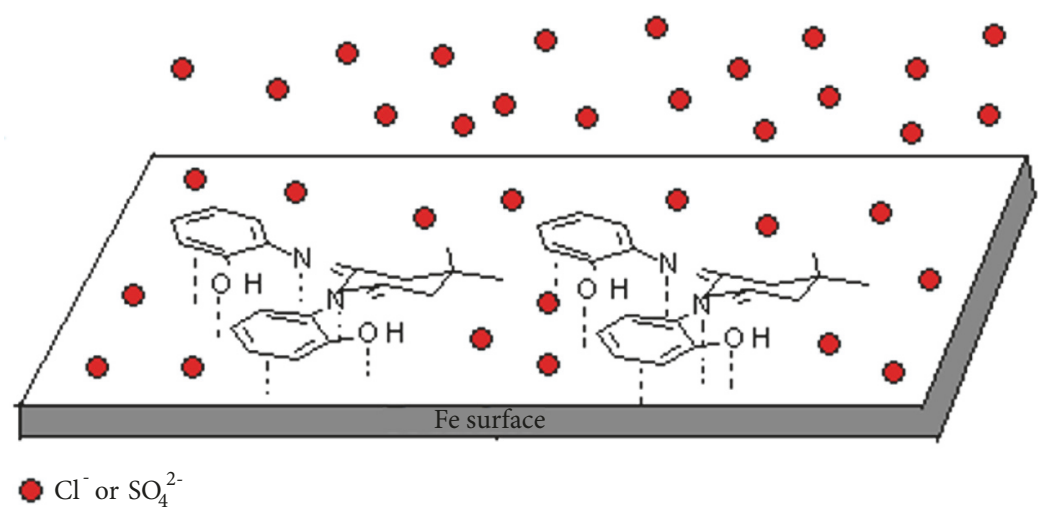

FIgURE 5: Interaction of DmChDp on mild steel in acid media.

3.2.4. Impact of Temperature. Temperature dependent gravimetric investigations definitely benchmark the mode of corrosion inhibition process. The degree of corrosion is dependent on temperature, remarkably in acid media associated with hydrogen evolution. In the present work, the impact of temperature on the inhibition process was investigated using weight loss studies for $24 \mathrm{~h}$ in $1 \mathrm{M} \mathrm{HCl}$ and $0.5 \mathrm{M} \mathrm{H}_{2} \mathrm{SO}_{4}$ with and without $\mathrm{DmChDp}$ at a temperature range $303-333 \mathrm{~K}$.

The activation energy of metal dissolution was measured using an Arrhenius type equation given below [30, 31]

$$
K=A \exp \left(-\frac{E a}{R T}\right)
$$

where $\mathrm{K}, \mathrm{A}, \mathrm{E}_{\mathrm{a}}$, R, and T represent corrosion rate, preexponential factor, activation energy, universal gas constant, and temperature in Kelvin, respectively.

Straight lines were obtained by plotting $\log \mathrm{K}$ versus $1 / \mathrm{T}$ for MS specimens in acid, with and without DmChDp, shown in Figures 6(a) and 7(a). The activation energy needed for the metal dissolution in $1 \mathrm{M} \mathrm{HCl}$ and $0.5 \mathrm{M} \mathrm{H}_{2} \mathrm{SO}_{4}$ was obtained from the slope of these plots. Thermodynamic parameters such as enthalpy $\left(\Delta H^{*}\right)$ and entropy $\left(\Delta S^{*}\right)$ were evaluated using transition state theory (equation $(6))[32,33]$.

$$
K=\left(\frac{R T}{N h}\right) \exp \left(\frac{\Delta \mathrm{S}^{*}}{R}\right) \exp \left(\frac{\Delta \mathrm{H}^{*}}{R T}\right)
$$

where $\mathrm{N}$ is the Avogadro number and $\mathrm{h}$ is the Planck's constant. Values of $\Delta \mathrm{H}^{*}$ and $\Delta \mathrm{S}^{*}$ were obtained from the slope
$-\Delta \mathrm{H}^{*} / 2.303 R$ and intercept $\log (R / 2.303 N h)+\Delta \mathrm{S}^{*} / 2.303 R$ of the plot between $\log \mathrm{K} / \mathrm{T}$ versus $1 / \mathrm{T}$ for the metal dissolution in $1 \mathrm{M} \mathrm{HCl}$ and $0.5 \mathrm{M} \mathrm{H}_{2} \mathrm{SO}_{4}$ (see Figures $6(\mathrm{~b})$ and $7(\mathrm{~b})$ ). The values of parameters such as activation energy $\left(\mathrm{E}_{\mathrm{a}}\right)$, enthalpy of activation $\left(\Delta \mathrm{H}^{*}\right)$, and entropy of activation $\left(\Delta \mathrm{S}^{*}\right)$ are given in Table 3. It was observed that the activation energy of corrosion in the presence of $\mathrm{DmChDp}$ was higher, compared to metal dissolution without DmChDp in $1 \mathrm{M} \mathrm{HCl}$ and $0.5 \mathrm{M} \mathrm{H}_{2} \mathrm{SO}_{4}$ [34]. The endothermic character of metal dissolution process was reflected from the positive sign of enthalpy. It is also observed that $\Delta \mathrm{H}^{*}$ and $\Delta \mathrm{S}^{*}$ increased with rise in concentration of DmChDp. In $0.5 \mathrm{M} \mathrm{H}_{2} \mathrm{SO}_{4}$ the entropy of activation for the metal dissolution was found to have negative values in the absence of $\mathrm{DmChDp}$ as well as at $0.2 \mathrm{mM}$ concentration. This mentions that the degree of randomness is low for the activated species, compared to the initial state. The randomness of activated complex goes up with rise in concentration of $\mathrm{DmChDp}$ and $\Delta \mathrm{S}^{*}$ acquired positive values.

\subsection{Electrochemical Studies}

3.3.1. EIS Measurements. The nature of corrosion inhibition of $\mathrm{DmChDp}$ on $\mathrm{MS}$ in $1 \mathrm{M} \mathrm{HCl}$ and $0.5 \mathrm{M} \mathrm{H}_{2} \mathrm{SO}_{4}$ was evaluated using electrochemical impedance spectroscopy at $28^{\circ} \mathrm{C}$. The impedance spectra of MS in the absence and presence of $\mathrm{DmChDp}$ at various concentrations in $1 \mathrm{M} \mathrm{HCl}$ and $0.5 \mathrm{M}$ 


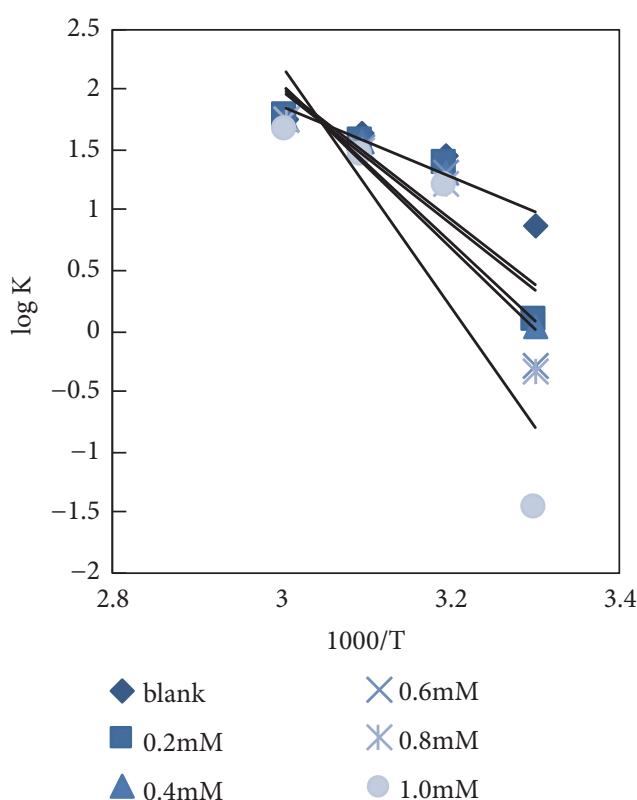

(a)

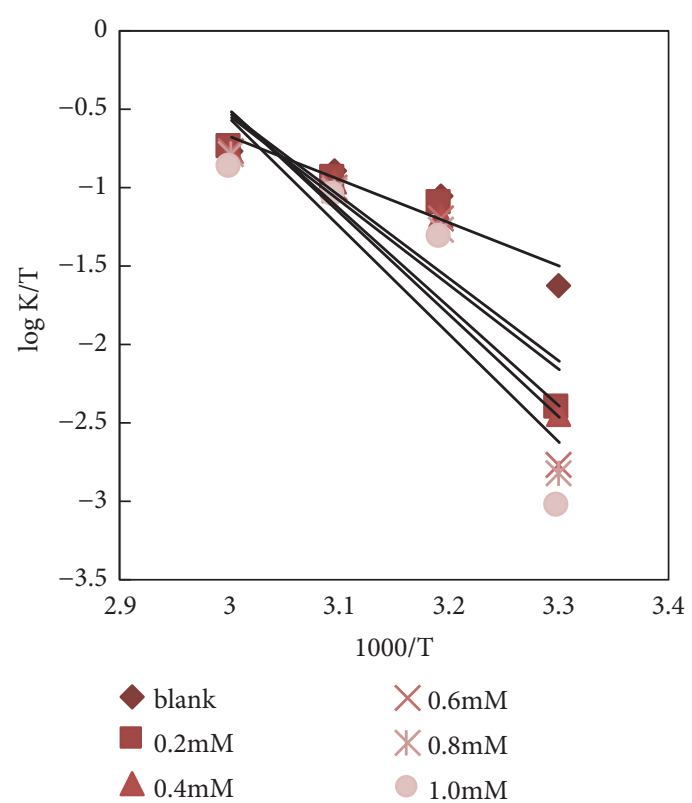

(b)

Figure 6: Plot of (a) $\log \mathrm{K}$ versus 1000/T (b) $\log \mathrm{K} / \mathrm{T}$ versus 1000/T with and without DmChDp in $1 \mathrm{M} \mathrm{HCl}$.

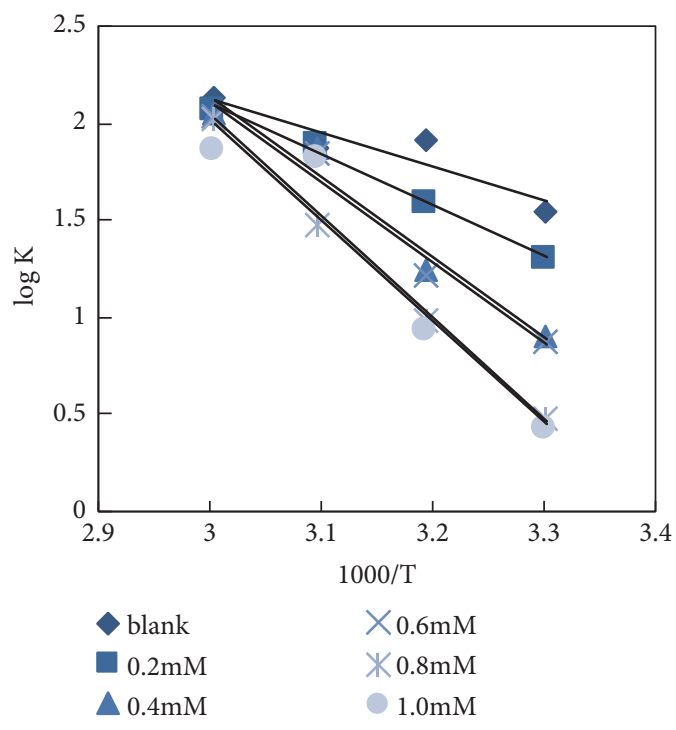

(a)

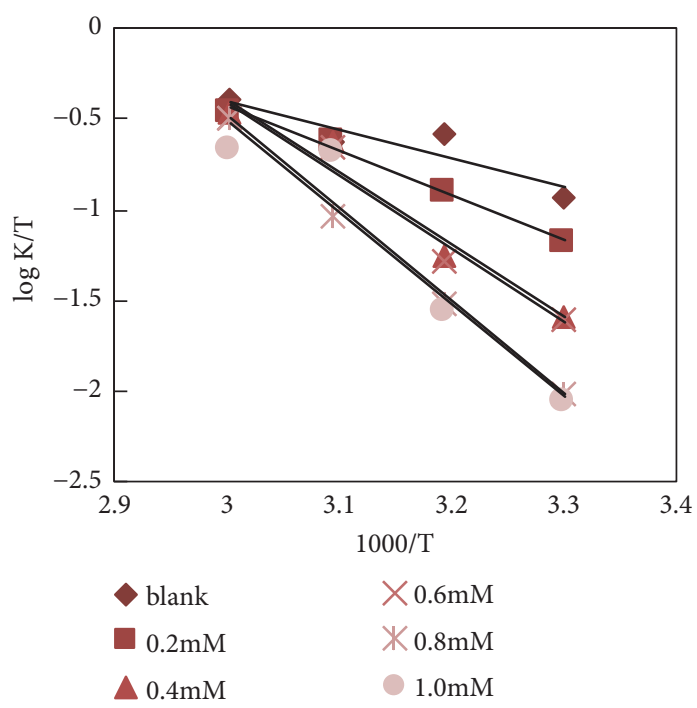

(b)

Figure 7: Plot of (a) $\log \mathrm{K}$ versus $1000 / \mathrm{T}$ (b) $\log \mathrm{K} / \mathrm{T}$ versus $1000 / \mathrm{T}$ with and without DmChDp in $0.5 \mathrm{M} \mathrm{H}_{2} \mathrm{SO}_{4}$.

$\mathrm{H}_{2} \mathrm{SO}_{4}$ are shown in Figures 8 and 9 (Nyquist and Bode plots). The impedance spectra showed a significant change on addition of DmChDp at various concentrations. The Nyquist plots of blank and treated specimen with DmChDp have similar shape but different size. This indicates that the mechanism of dissolution of metal is same in both cases. The sizes of the Nyquist plots were found to be increased with rise in concentration of $\mathrm{DmChDp}$, which indicates that the impedance of MS increased when the concentration increased.

The inhibition potency also increased with concentration. The equivalent circuit used to fit the Nyquist plots (Randles circuit) is shown in Figure 10. The circuit consists of a double layer capacitance $\mathrm{C}_{\mathrm{dl}}$, solution resistance $\mathrm{R}_{\mathrm{s}}$, and charge transfer resistance $R_{c t}$ [35-38]. Constant phase element (CPE) is inserted into the circuit in preference to pure double layer 

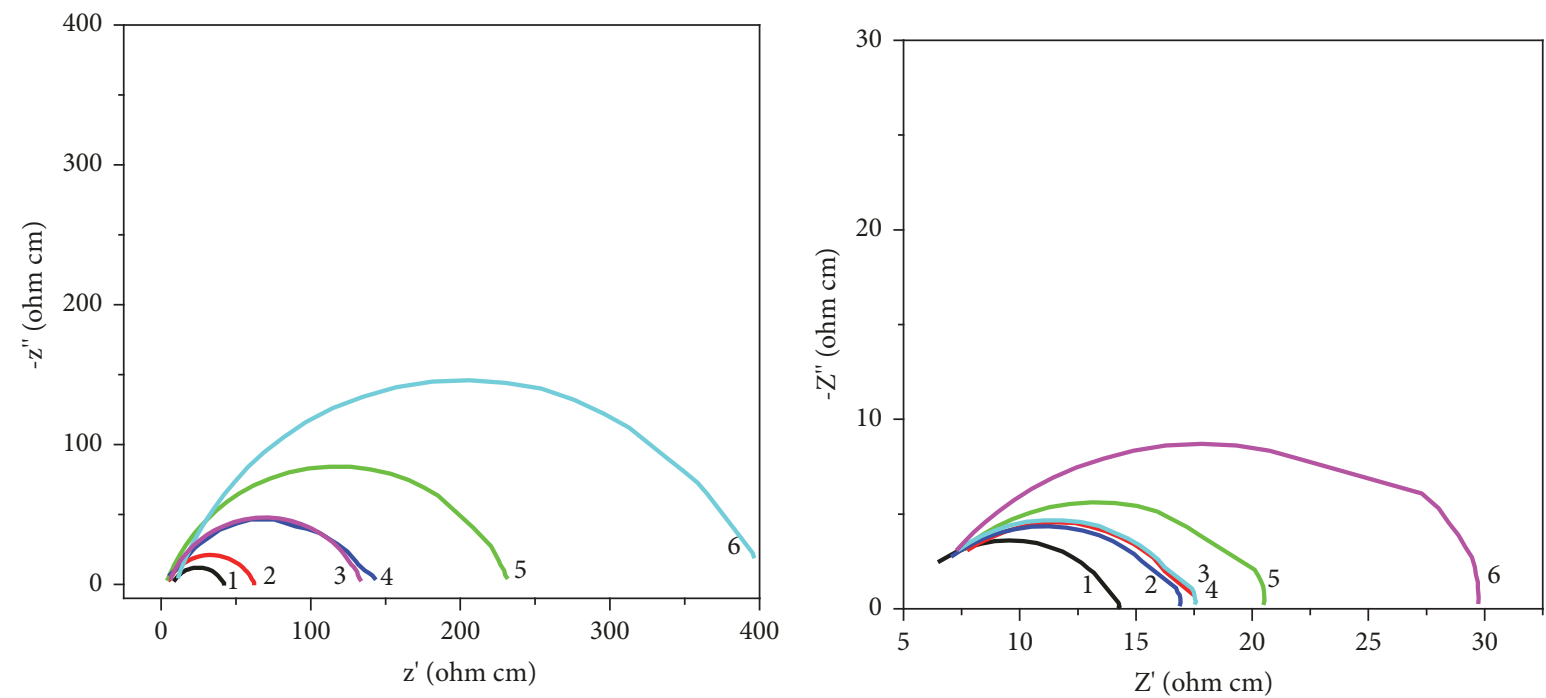

$$
\begin{aligned}
& \text { 1) blank } \\
& \text { 2) } 0.2 \mathrm{mM} \\
& \text { 3) } 0.4 \mathrm{mM} \\
& \text { 4) } 0.6 \mathrm{mM} \\
& \text { 5) } 0.8 \mathrm{mM} \\
& \text { 6) } 1.0 \mathrm{mM}
\end{aligned}
$$

\begin{tabular}{|c|c|c|c|c|c|}
\hline $\begin{array}{l}\text { Acid } \\
\text { medium }\end{array}$ & $\begin{array}{l}\text { Conc } \\
(\mathrm{mM})\end{array}$ & $\begin{array}{c}\mathrm{E}_{\mathrm{a}} \\
\left(\mathrm{KJ} \mathrm{mol}^{-1}\right) \\
\end{array}$ & A & $\begin{array}{c}\Delta \mathrm{H}^{*} \\
\left(\mathrm{KJ} \mathrm{mol}^{-1}\right) \\
\end{array}$ & $\begin{array}{c}\Delta \mathrm{S}^{*} \\
\left(\mathrm{~J} \mathrm{~mol}^{-1} \mathrm{~K}^{-1}\right)\end{array}$ \\
\hline \multirow{6}{*}{$\mathrm{HCl}$} & Blank & 55.7 & $3.81 \times 10^{10}$ & 53.03 & -44.26 \\
\hline & 0.2 & 103.04 & $1.40 \times 10^{18}$ & 100.40 & 100.59 \\
\hline & 0.4 & 105.58 & $3.38 \times 10^{18}$ & 102.94 & 107.92 \\
\hline & 0.6 & 123.53 & $2.43 \times 10^{21}$ & 120.89 & 162.60 \\
\hline & 0.8 & 127.55 & $1.01 \times 10^{22}$ & 124.91 & 174.49 \\
\hline & 1 & 134.58 & $1.16 \times 10^{23}$ & 131.9 & 194.77 \\
\hline \multirow{6}{*}{$\mathrm{H}_{2} \mathrm{SO}_{4}$} & Blank & 33.1 & $2.08 \times 10^{7}$ & 30.5 & -106.71 \\
\hline & 0.2 & 50.24 & $9.96 \times 10^{9}$ & 47.60 & -55.97 \\
\hline & 0.4 & 79.40 & $14.57 \times 10^{14}$ & 76.76 & 32.16 \\
\hline & 0.6 & 79.43 & $14.55 \times 10^{14}$ & 76.79 & 31.81 \\
\hline & 0.8 & 99.57 & $17.61 \times 10^{17}$ & 96.93 & 90.36 \\
\hline & 1 & 100.93 & $17.85 \times 10^{17}$ & 98.29 & 95.07 \\
\hline
\end{tabular}

$$
\begin{aligned}
& \text { 1) blank } \\
& \text { 2) } 0.2 \mathrm{mM} \\
& \text { 3) } 0.4 \mathrm{mM} \\
& \text { 4) } 0.6 \mathrm{mM} \\
& \text { 5) } 0.8 \mathrm{mM} \\
& \text { 6) } 1.0 \mathrm{mM}
\end{aligned}
$$

(a)

(b)

FIGURE 8: Nyquist plots of MS coupons with and without DmChDp in (a) $1 \mathrm{M} \mathrm{HCl}$ and (b) $0.5 \mathrm{M} \mathrm{H}_{2} \mathrm{SO}_{4}$.

TABLE 3: Thermodynamic parameters of corrosion of MS with and without DmChDp in $1 \mathrm{M} \mathrm{HCl}$ and $0.5 \mathrm{M} \mathrm{H}_{2} \mathrm{SO}_{4}$.

capacitance to lower the effects due to deformities on the surface of metal as shown in Figure 10 [39]. The impedance of CPE can be expressed as $[40,41]$

$$
Z_{C P E}=\frac{1}{Y_{0}(j \omega)^{n}}
$$

where $\mathrm{Y}_{0}$ is the magnitude of CPE, $\mathrm{n}$ is the exponent (phase shift), $\omega$ is the angular frequency, and $j$ is the imaginary unit. Based on the values of $n$, CPE can be capacitance, inductance, and resistance. It is observed that the values of $\mathrm{n}$ are between
0.75 and 1.0, indicating the nature of capacitance of CPE. The impedance data such as $\mathrm{R}_{\mathrm{ct}}$, $\mathrm{CPE}$, and the percentage of inhibition potency $\left(\eta_{\mathrm{EIS}} \%\right)$ of DmChDp are listed in Table 4.

Charge transfer resistance $\left(\mathrm{R}_{\mathrm{ct}}\right)$ is found to be increased with DmChDp concentration whereas capacitance $\left(\mathrm{C}_{\mathrm{dl}}\right)$ value is reduced. The increase of $\mathrm{R}_{\mathrm{ct}}$ value is more in the case of $1 \mathrm{M} \mathrm{HCl}$. The decrease in $\mathrm{C}_{\mathrm{dl}}$ values is due to the lowering of local dielectric constant and/or increase in thickness of electrical double layer [42]. The maximum inhibition potency of $91.66 \%$ is observed at $1 \mathrm{mM}$ concentration of $\mathrm{DmChDp}$ in $1 \mathrm{M} \mathrm{HCl}$ whereas it is only $58.76 \%$ in $0.5 \mathrm{M} \mathrm{H}_{2} \mathrm{SO}_{4}$. 


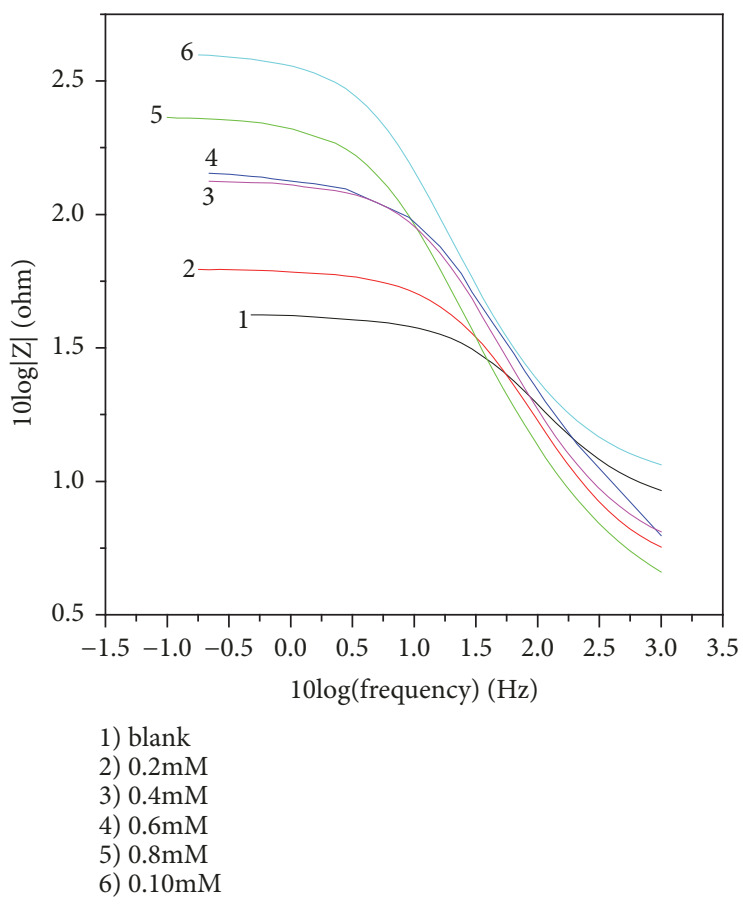

(a)

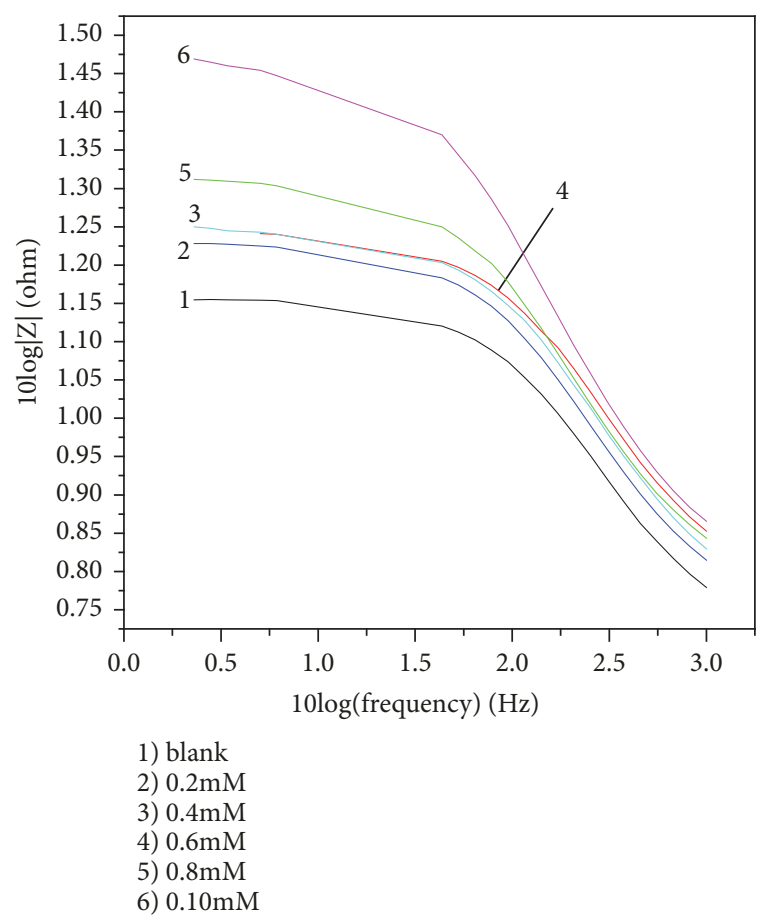

(b)

FIGURE 9: Bode plots of MS coupons with and without DmChDp in (a) $1 \mathrm{M} \mathrm{HCl}$ and (b) $0.5 \mathrm{M} \mathrm{H}_{2} \mathrm{SO}_{4}$.

TABLE 4: Impedance data of MS coupons with and without DmChDp in $1 \mathrm{M} \mathrm{HCl}$ and $0.5 \mathrm{M} \mathrm{H}_{2} \mathrm{SO}_{4}$.

\begin{tabular}{|c|c|c|c|c|c|c|}
\hline \multirow{2}{*}{$\begin{array}{l}\text { Conc } \\
(\mathrm{mM})\end{array}$} & \multirow[b]{2}{*}{$\begin{array}{c}\mathrm{R}_{\mathrm{ct}} \\
\left(\Omega \mathrm{cm}^{2}\right)\end{array}$} & \multirow{2}{*}{$\begin{array}{c}1 \mathrm{M} \mathrm{HCl} \\
\mathrm{C}_{\mathrm{dl}} \\
\left(\mu \mathrm{Fcm}^{-2}\right)\end{array}$} & \multicolumn{4}{|c|}{$0.5 \mathrm{M} \mathrm{H}_{2} \mathrm{SO}_{4}$} \\
\hline & & & $\eta_{\mathrm{EIS}} \%$ & $\begin{array}{c}\mathrm{R}_{\mathrm{ct}} \\
\left(\Omega \mathrm{cm}^{2}\right)\end{array}$ & $\begin{array}{c}\mathrm{C}_{\mathrm{dl}} \\
\left(\mu \mathrm{Fcm}^{-2}\right)\end{array}$ & $\eta_{\mathrm{EIS}} \%$ \\
\hline 0 & 29.1 & 105 & & 7.96 & 113 & \\
\hline 0.2 & 50.5 & 97.7 & 42.37 & 13.1 & 72.8 & 39.23 \\
\hline 0.4 & 114 & 82.8 & 74.47 & 14.6 & 67.7 & 45.48 \\
\hline 0.6 & 117 & 82 & 75.12 & 14.9 & 66.5 & 46.57 \\
\hline 0.8 & 202 & 73.2 & 85.59 & 17.5 & 53.2 & 54.51 \\
\hline 1 & 349 & 64.6 & 91.66 & 19.3 & 41.6 & 58.76 \\
\hline
\end{tabular}

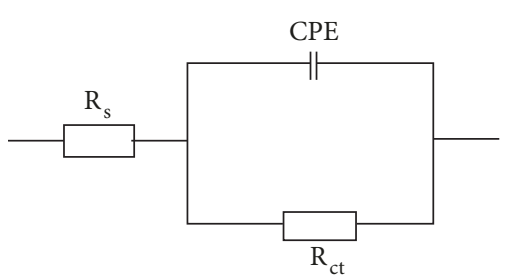

FIGURE 10: Randles circuit used for EIS measurements.

3.3.2. Potentiodynamic Polarization Studies. Polarization data such as corrosion potential $\left(\mathrm{E}_{\mathrm{corr}}\right)$, corrosion current densities $\left(\mathrm{I}_{\text {corr }}\right)$, cathodic slope $\left(\mathrm{b}_{\mathrm{c}}\right)$, anodic slope $\left(\mathrm{b}_{\mathrm{a}}\right)$, and inhibition potency $\left(\eta_{\text {pol }} \%\right)$ of DmChDp in $1 \mathrm{M} \mathrm{HCl}$ and $0.5 \mathrm{M}$ $\mathrm{H}_{2} \mathrm{SO}_{4}$ are listed in Table 5. Polarization curves in both acid media are shown in Figure 11.
From the polarization data it is understandable that corrosion current density decreased with the concentration of $\mathrm{DmChDp}$; as a result, the percentage inhibition potency increased. A maximum inhibition efficiency of $94.87 \%$ and $50.79 \%$ was shown by $\mathrm{DmChDp}$ at $1 \mathrm{mM}$ concentration in $1 \mathrm{M} \mathrm{HCl}$ and $0.5 \mathrm{M} \mathrm{H}_{2} \mathrm{SO}_{4}$ respectively. The $b_{\mathrm{a}}$ and $\mathrm{b}_{\mathrm{c}}$ values showed that addition of $\mathrm{DmChDp}$ to acid media affected both cathodic and anodic parts of the curves and acted as a mixed type inhibitor [43, 44].

The evaluated corrosion inhibition efficiency of DmChDp according to gravimetric studies in $\mathrm{H}_{2} \mathrm{SO}_{4}$ medium was higher than that of EIS and potentiodynamic polarization investigations. This can be explained by the following mechanism. The molecular structure of DmChDp consists of two azomethine linkages. In general, azomethine bonds are susceptible to hydrolysis in acidic medium. Due to the puckered nature of $\mathrm{DmChDp}$, it cannot interact well 

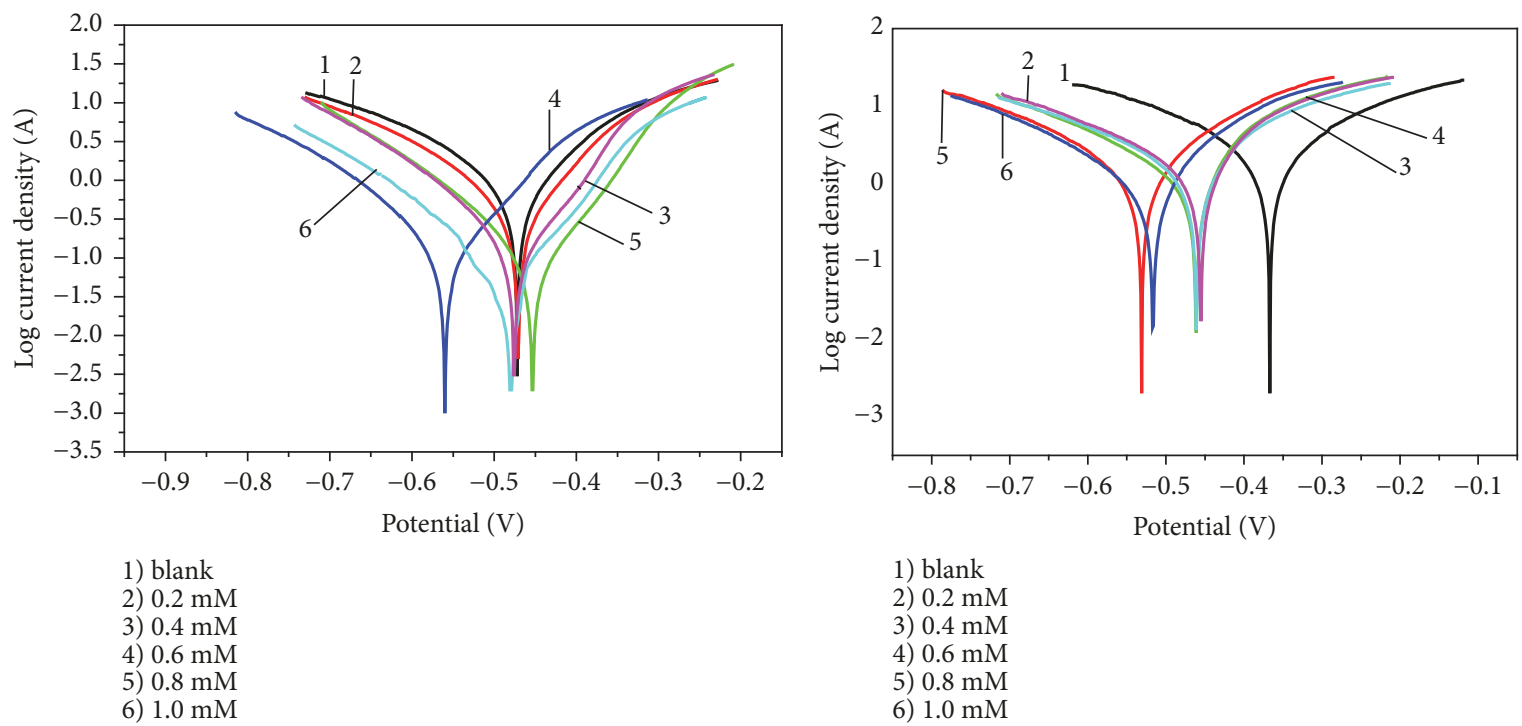

(a)

(b)

FIGURE 11: Tafel plots of MS coupons with and without DmChDp in (a) $1 \mathrm{M} \mathrm{HCl}$ and (b) $0.5 \mathrm{M} \mathrm{H}_{2} \mathrm{SO}_{4}$.

TABLE 5: Polarization data of MS coupons with and without DmChDp inlM $\mathrm{HCl}$ and $0.5 \mathrm{M} \mathrm{H}_{2} \mathrm{SO}_{4}$.

\begin{tabular}{|c|c|c|c|c|c|c|}
\hline \multirow[b]{2}{*}{ Acid } & \multicolumn{6}{|c|}{ Tafel data } \\
\hline & $\begin{array}{l}\text { Conc } \\
(\mathrm{mM})\end{array}$ & $\begin{array}{l}E_{\text {corr }} \\
(\mathrm{mV})\end{array}$ & $\begin{array}{c}\mathrm{I}_{\text {corr }} \\
(\mu \mathrm{A} / \mathrm{cm} 2)\end{array}$ & $\begin{array}{c}\mathrm{b}_{\mathrm{a}} \\
(\mathrm{mV} / \mathrm{dec})\end{array}$ & $\begin{array}{c}-\mathrm{b}_{\mathrm{c}} \\
(\mathrm{mV} / \mathrm{dec})\end{array}$ & $\% \eta_{\text {pol }}$ \\
\hline $\mathrm{HCl}$ & 0 & -477.3 & 1160 & 172 & 212 & \\
\hline \multirow{5}{*}{$\mathrm{HCl}$} & 0.2 & -473.5 & 640 & 138 & 185 & 44.82 \\
\hline & 0.4 & -461.4 & 172 & 83 & 141 & 85.21 \\
\hline & 0.6 & -547.2 & 163 & 104 & 150 & 85.97 \\
\hline & 0.8 & -432.2 & 98.9 & 73 & 135 & 91.47 \\
\hline & 1 & -471.5 & 59.5 & 79 & 130 & 94.87 \\
\hline $\mathrm{H}_{2} \mathrm{SO}_{4}$ & 0 & -374.3 & 2528 & 241 & 242 & \\
\hline \multirow{5}{*}{$\mathrm{H}_{2} \mathrm{SO}_{4}$} & 0.2 & -500.5 & 2282 & 253 & 243 & 9.73 \\
\hline & 0.4 & -496.3 & 2058 & 257 & 251 & 18.47 \\
\hline & 0.6 & -514.5 & 1957 & 244 & 219 & 22.59 \\
\hline & 0.8 & -538.3 & 1563 & 185 & 222 & 38.17 \\
\hline & 1 & -539.9 & 1244 & 185 & 205 & 50.79 \\
\hline
\end{tabular}

on the metal surface. Slow hydrolysis of $\mathrm{DmChDp}$ in $0.5 \mathrm{M}$ $\mathrm{H}_{2} \mathrm{SO}_{4}$ medium was confirmed by UV-visible spectroscopy. It can be assumed that large number of $\mathrm{DmChDp}$ molecules did not undergo appreciable structural degradation for 1-2 $h$ and thus exhibit poor corrosion inhibition potency on MS according to electrochemical studies. On keeping the Schiff base in $0.5 \mathrm{M} \mathrm{H}_{2} \mathrm{SO}_{4}$ medium for a long time, it can be imagined that partial hydrolysis of the molecule takes place (for one $\mathrm{C}=\mathrm{N}$ linkage only). This structural degradation of DmChDp may be highly beneficial to interact effectively on the MS surface, since the bulky nature of the molecule is appreciably lowered. The electron rich aromatic ring and the $\mathrm{C}=\mathrm{N}$ linkage now can make coordinate type bonds with the surface metal atoms easily. Thus after a period of 24 $\mathrm{h}$, DmChDp molecule showed much enhanced corrosion inhibition efficiency on MS surface.
3.4. Scanning Electron Microscopy (SEM). The surface morphological studies of the MS coupons were done by scanning electron microscope. Figures 12(a)-12(e) represent the SEM images of $\mathrm{MS}$ in $1 \mathrm{M} \mathrm{HCl}$ and $0.5 \mathrm{M} \mathrm{H}_{2} \mathrm{SO}_{4}$ in the presence and absence of DmChDp (1mM). The morphological studies clearly established the surface of the polished mild steel coupon before treatment in acid solution was smooth and not corroded as shown in Figure 12(a). Significant change in the surface morphology was noticed after immersion in aggressive medium without inhibitor. It is clear from Figures 12(b) and 12(c) that corrosion is more prominent in $0.5 \mathrm{M} \mathrm{H}_{2} \mathrm{SO}_{4}$, compared to that in $1 \mathrm{M} \mathrm{HCl}$. However in the presence of $1 \mathrm{mM}$ concentration of $\mathrm{DmChDp}$ the rate of corrosion was decreased and the surface deterioration has been reduced (Figures 12(d) and 12(e)). This is due to the surface coverage of the inhibitor molecule containing imino 


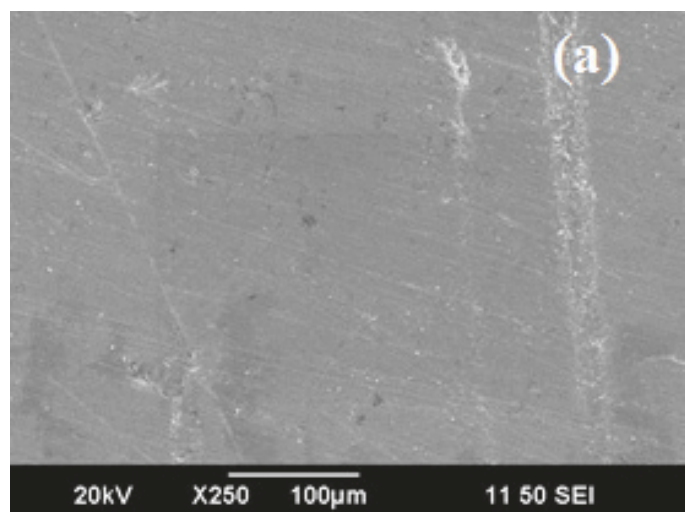

(a)

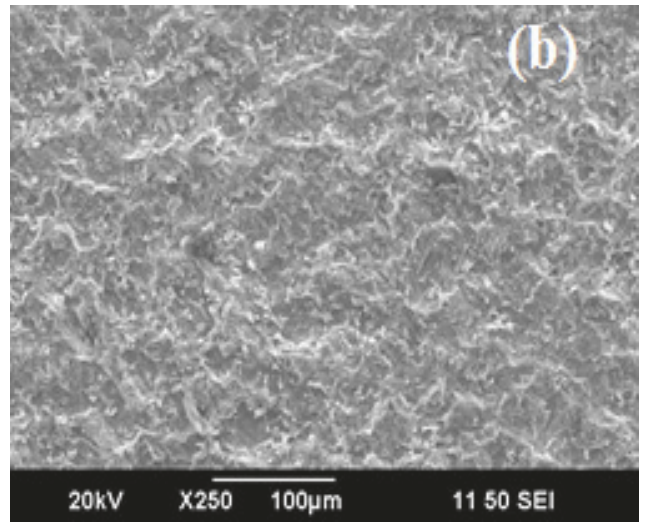

(b)

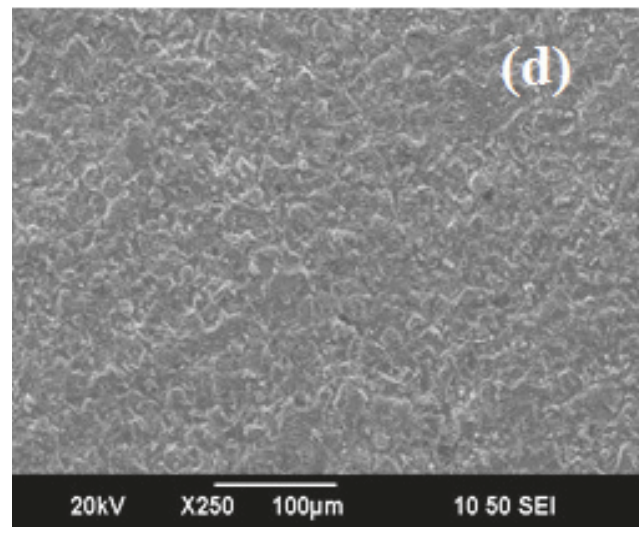

(d)

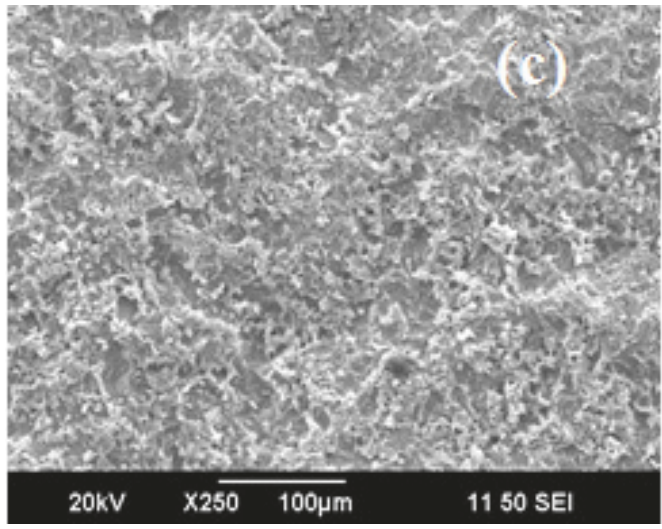

(c)

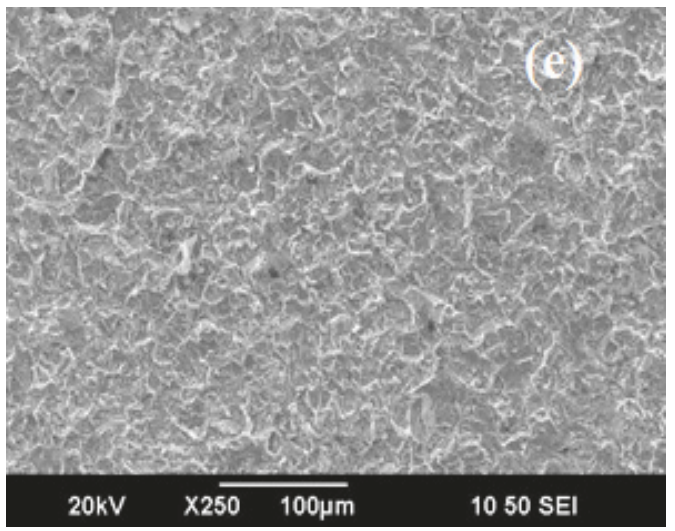

(e)

FIGURE 12: SEM analysis of MS coupons before and after $24 \mathrm{~h}$ immersion: (a) bare, (b) blank ( $\mathrm{HCl}),(\mathrm{c})$ blank $\left(\mathrm{H}_{2} \mathrm{SO}_{4}\right),(\mathrm{d})$ treated with DmChDp (1mM) in $1 \mathrm{M} \mathrm{HCl}$, (e) treated with $\mathrm{DmChDp}(1 \mathrm{mM})$ in $0.5 \mathrm{M} \mathrm{H}_{2} \mathrm{SO}_{4}$.

group. The aromatic rings and the azomethine linkage play great role in preventing dissolution of the metal and thereby protecting the mild steel from corrosion.

\section{Conclusions}

(1) DmChDp is an excellent corrosion inhibitor for MS in $1 \mathrm{M} \mathrm{HCl}$.
(2) The maximum inhibition potency of $\mathrm{DmChDp}$ was $94.01 \%$ and $92.46 \%$ in $1 \mathrm{M} \mathrm{HCl}$ and $0.5 \mathrm{M} \mathrm{H}_{2} \mathrm{SO}_{4}$ respectively according to weight loss measurements.

(3) DmChDp exhibited very high corrosion inhibition potency, compared to the parent ketone, 5,5dimethyl-1,3-cyclohexanedione and parent amine, 2aminophenol. 
(4) In both acid media DmChDp obeys Langmuir adsorption isotherm.

(5) $\Delta G^{0}$ ads value shows that the adsorption has both physical and chemical nature.

(6) The activation energy of corrosion in the presence of DmChDp was higher, compared to metal dissolution without $\mathrm{DmChDp}$ in $1 \mathrm{M} \mathrm{HCl}$ and $0.5 \mathrm{M} \mathrm{H}_{2} \mathrm{SO}_{4}$. This implies that metal dissolution decreased with increase in inhibitor concentration due to adsorption of inhibitor on mild steel coupon.

(7) Polarization data showed that $\mathrm{DmChDp}$ acts as mixed type inhibitor in both acid media.

(8) CV studies reveal the irreversible nature of electron transfer processes.

(9) The formation of protective layer on the MS was confirmed by surface morphological studies (SEM).

\section{Data Availability}

No data were used to support this study.

\section{Conflicts of Interest}

The authors declare that they have no conflicts of interest.

\section{Acknowledgments}

Authors are grateful to Council of Scientific \& Industrial Research (CSIR) for providing financial assistance for the research work.

\section{Supplementary Materials}

Characteristic stretching frequencies of various bonds in $\mathrm{DmChDp}$ were obtained from the IR spectrum. The azomethine moiety $(\mathrm{C}=\mathrm{N})$ was identified by the peak at $1600 \mathrm{~cm}^{-1}$. A band at $3080 \mathrm{~cm}^{-1}$ was due to the aromatic C-H bond stretching vibration. $v_{\mathrm{C}-\mathrm{O}}$ was observed at $1238 \mathrm{~cm}^{-1} \cdot v_{\mathrm{C}=\mathrm{C}}$ stretching vibration of the aromatic ring was observed at 1564 and $1514 \mathrm{~cm}^{-1}$. A band at $3240 \mathrm{~cm}^{-1}$ indicates the stretching vibration of $\mathrm{OH}$ group. The $\mathrm{C}-\mathrm{H}$ bond involving sp3 hybridized carbon gave characteristic bands at 2960 and $2877 \mathrm{~cm}^{-1}$. A peak at $1450 \mathrm{~cm}^{-1}$ corresponds to C-H bending vibration. In plane deformation was observed at 1147,1114 , and $1037 \mathrm{~cm}^{-1}$. Out of plane deformation was observed at 763 and $650 \mathrm{~cm}^{-1}$. Eight nonequivalent hydrogen atoms which were in different electronic environments gave characteristic peaks in the proton NMR spectrum. A peak obtained at $0.999 \delta$ can be assigned to $\mathrm{CH}_{3}$ group present in the cyclohexane ring. The $\mathrm{CH}_{2}$ group adjacent to the carbon containing $\mathrm{CH}_{3}$ group showed a peak at $2.022 \delta$. The peak at $2.356 \delta$ is assigned to the proton present in the carbon between two azomethine moieties. A broad peak at $9.877 \delta$ corresponds to $\mathrm{OH}$ proton. The aromatic protons gave characteristic peaks at 6.819-7.078 $\delta$. The appearance of a weak signal at $8.397 \delta$ due to the $\mathrm{NH}$ proton and peak at $4.864 \delta$ due to olefinic $\mathrm{CH}$ confirmed the existence of tautomerism. The presence of eleven chemically different carbon atoms was confirmed by ${ }^{13} \mathrm{C} \mathrm{NMR}$ spectrum. The azomethine carbon was identified at $95.88 \mathrm{ppm}$. The aromatic carbons of the benzene ring exhibited six signals in the range $116.28-151.55 \mathrm{ppm}$. Methylene carbon atoms labelled 3 and 5 exhibited their peaks at $32.329 \mathrm{ppm}$ and 49.783ppm, respectively. Methyl carbon atom exhibited a signal at 27.841ppm. Molecular ion peak at $\mathrm{m} / \mathrm{z} 322$ was absent. Base peak was observed at $\mathrm{m} / \mathrm{z} 216$, which is formed by the loss of amino phenolic moiety from the molecule. Loss of one phenolic moiety resulted in a peak at $\mathrm{m} / \mathrm{z} 231$ which corresponds to $\left[\mathrm{C}_{14} \mathrm{H}_{19} \mathrm{~N}_{2} \mathrm{O}\right]^{+}$. Peaks at $\mathrm{m} / \mathrm{z} 178,160,146,133$, and 109 were due to the fragments $\left[\mathrm{C}_{11} \mathrm{H}_{16} \mathrm{~N} \mathrm{O}\right]^{+},\left[\mathrm{C}_{9} \mathrm{H}_{8} \mathrm{~N}_{2}\right.$ $\mathrm{O}]^{+},\left[\mathrm{C}_{9} \mathrm{H}_{10} \mathrm{~N}_{2}\right]^{+},\left[\mathrm{C}_{8} \mathrm{H}_{7} \mathrm{NO}\right]^{+}$, and $\left[\mathrm{C}_{6} \mathrm{H}_{9} \mathrm{~N}_{2}\right]^{+}$, respectively. (Supplementary Materials)

\section{References}

[1] D. Gopi, K. M. Govindaraju, and L. Kavitha, "Investigation of triazole derived Schiff bases as corrosion inhibitors for mild steel in hydrochloric acid medium," Journal of Applied Electrochemistry, vol. 40, no. 7, pp. 1349-1356, 2010.

[2] X. Wang, Y. Wang, Q. Wang, Y. Wan, X. Huang, and C. Jing, "Viburnum Sargentii Koehne fruit extract as corrosion inhibitor for mild steel in acidic solution," International Journal of Electrochemical Science, vol. 13, no. 6, pp. 5228-5242, 2018.

[3] M. P. Chakravarthy and K. N. Mohana, "Adsorption and corrosion inhibition characteristics of some nicotinamide derivatives on mild steel in hydrochloric acid solution," ISRN Corrosion, vol. 2014, Article ID 687276, 13 pages, 2014.

[4] A. K. Singh, S. K. Shukla, and M. A. Quraishi, "Corrosion behaviour of mild steel in sulphuric acid solution in presence of ceftazidime," International Journal of Electrochemical Science, vol. 6, no. 11, pp. 5802-5814, 2011.

[5] V. P. Raphael, K. S. Shaju, and K. J. Thomas, "Monitoring the interaction of two heterocyclic compounds on carbon steel by electrochemical polarization, noise, and quantum chemical studies," International Journal of Corrosion, vol. 2016, Article ID 4204532, 10 pages, 2016.

[6] Z. Tao, S. Zhang, W. Li, and B. Hou, "Adsorption and corrosion inhibition behavior of mild steel by one derivative of benzoictriazole in acidic solution," Industrial \& Engineering Chemistry Research, vol. 49, no. 6, pp. 2593-2599, 2010.

[7] S. John and A. Joseph, "Electro analytical, surface morphological and theoretical studies on corrosion inhibition behaviour of different 1,2,4-triazole precursors on mild steel in $1 \mathrm{M}$ hydrochloric acid," Materials Chemistry and Physics, vol. 133, no. 2-3, pp. 1083-1091, 2012.

[8] S. Deng, X. Li, and H. Fu, "Alizarin violet 3B as a novel corrosion inhibitor for steel in $\mathrm{HCl}, \mathrm{H}_{2} \mathrm{SO}_{4}$ solutions," Corrosion Science, vol. 53, no. 11, pp. 3596-3602, 2011.

[9] H. Ashassi-Sorkhabi, E. Asghari, and P. Ejbari, "Electrochemical studies of adsorption and inhibitive performance of basic yellow 28 dye on mild steel corrosion in acid solutions," Acta Chimica Slovenica, vol. 58, no. 2, pp. 270-277, 2011.

[10] H. Kaleş, M. Keleş, I. Dehri, and O. Serindag, "The inhibitive effect of 6-amino-m-cresol and its Schiff base on the corrosion of mild steel in 0.5 M HCI medium," Materials Chemistry and Physics, vol. 112, no. 1, pp. 173-179, 2008. 
[11] P. Lowmunkhong, D. Ungthararak, and P. Sutthivaiyakit, "Tryptamine as a corrosion inhibitor of mild steel in hydrochloric acid solution," Corrosion Science, vol. 52, no. 1, pp. 30-36, 2010.

[12] K. R. Ansari, M. A. Quraishi, and A. Singh, "Isatin derivatives as a non-toxic corrosion inhibitor for mild steel in $20 \% \mathrm{H}_{2} \mathrm{SO}_{4}$," Corrosion Science, vol. 95, pp. 62-70, 2015.

[13] I. Ahamad, C. Gupta, R. Prasad, and M. A. Quraishi, "An experimental and theoretical investigation of adsorption characteristics of a Schiff base compound as corrosion inhibitor at mild steel/hydrochloric acid interface," Journal of Applied Electrochemistry, vol. 40, no. 12, pp. 2171-2183, 2010.

[14] N. Raman, S. Ravichandran, and C. Thangaraja, "Copper(II), cobalt(II), nickel(II) and zinc(II) complexes of Schiff base derived from benzyl-2,4-dinitrophenylhydrazone with aniline," Journal of Chemical Sciences, vol. 116, no. 4, pp. 215-219, 2004.

[15] C. B. Verma, M. A. Quraishi, and A. Singh, "2-Aminobenzene1,3-dicarbonitriles as green corrosion inhibitor for mild steel in $1 \mathrm{M} \mathrm{HCl}$ : Electrochemical, thermodynamic, surface and quantum chemical investigation," Journal of the Taiwan Institute of Chemical Engineers, vol. 49, pp. 229-239, 2015.

[16] K. M. Govindaraju, D. Gopi, and L. Kavitha, "Inhibiting effects of 4-amino-antipyrine based schiff base derivatives on the corrosion of mild steel in hydrochloric acid," Journal of Applied Electrochemistry, vol. 39, no. 12, pp. 2345-2352, 2009.

[17] S. K. Saha, A. Dutta, P. Ghosh, D. Sukul, and P. Banerjee, "Adsorption and corrosion inhibition effect of schiff base molecules on the mild steel surface in $1 \mathrm{M} \mathrm{HCL}$ medium: A combined experimental and theoretical approach," Physical Chemistry Chemical Physics, vol. 17, no. 8, pp. 5679-5690, 2015.

[18] A. Y. Musa, A. B. Mohamad, A. A. H. Kadhum, M. S. Takriff, and L. T. Tien, "Synergistic effect of potassium iodide with phthalazone on the corrosion inhibition of mild steel in $1.0 \mathrm{M}$ HCl," Corrosion Science, vol. 53, no. 11, pp. 3672-3677, 2011.

[19] S. John, B. Joseph, K. K. Aravindakshan, and A. Joseph, "Inhibition of mild steel corrosion in $1 \mathrm{M}$ hydrochloric acid by 4 -(N,N-dimethylaminobenzilidine)-3-mercapto-6-methyl1,2,4-triazin(4H)-5-one (DAMMT)," Materials Chemistry and Physics, vol. 122, no. 2-3, pp. 374-379, 2010.

[20] A. Pandey, B. Singh, C. Verma, and E. E. Ebenso, "Synthesis, characterization and corrosion inhibition potential of two novel Schiff bases on mild steel in acidic medium," RSC Advances, vol. 7, no. 74, pp. 47148-47163, 2017.

[21] K. S. Shaju, J. Thomas K, V. P Raphael, and N. Kuriakose, "Spectral and cyclic voltammetricstudies on $\mathrm{Cu}$ (II)-schiff base complex derived from anthracene-9(10 H)-one," IOSR Journal of Applied Chemistry, vol. 7, no. 10, pp. 64-68, 2014.

[22] V. P. Raphael, K. J. Thomas, K. S. Shaju, and A. Paul, "Corrosion inhibition investigations of 3-acetylpyridine semicarbazone on carbon steel in hydrochloric acid medium," Research on Chemical Intermediates, vol. 40, no. 8, pp. 2689-2701, 2014.

[23] K. S. Jacob and G. Parameswaran, "Corrosion inhibition of mild steel in hydrochloric acid solution by Schiff base furoin thiosemicarbazone," Corrosion Science, vol. 52, no. 1, pp. 224228, 2010.

[24] S. Issaadi, T. Douadi, A. Zouaoui, S. Chafaa, M. A. Khan, and G. Bouet, "Novel thiophene symmetrical Schiff base compounds as corrosion inhibitor for mild steel in acidic media," Corrosion Science, vol. 53, no. 4, pp. 1484-1488, 2011.

[25] X. Li, S. Deng, H. Fu, and T. Li, "Adsorption and inhibition effect of 6-benzylaminopurine on cold rolled steel in 1.0 M HCl," Electrochimica Acta, vol. 54, no. 16, pp. 4089-4098, 2009.
[26] A. Ghanbari, M. M. Attar, and M. Mahdavian, "Corrosion inhibition performance of three imidazole derivatives on mild steel in $1 \mathrm{M}$ phosphoric acid," Materials Chemistry and Physics, vol. 124, no. 2-3, pp. 1205-1209, 2010.

[27] S. A. Umoren, "Synergistic inhibition effect of polyethylene glycol-polyvinyl pyrrolidone blends for mild steel corrosion in sulphuric acid medium," Journal of Applied Polymer Science, vol. 119, no. 4, pp. 2072-2084, 2011.

[28] X. Wang, H. Yang, and F. Wang, "An investigation of benzimidazole derivative as corrosion inhibitor for mild steel in different concentration $\mathrm{HCl}$ solutions," Corrosion Science, vol. 53, no. 1, pp. 113-121, 2011.

[29] X. Li, S. Deng, and H. Fu, "Synergism between red tetrazolium and uracil on the corrosion of cold rolled steel in $\mathrm{H}_{2} \mathrm{SO}_{4}$ solution," Corrosion Science, vol. 51, no. 6, pp. 1344-1355, 2009.

[30] G. E. Badr, "The role of some thiosemicarbazide derivatives as corrosion inhibitors for C-steel in acidic medium," Corrosion Science, vol. 51, no. 11, pp. 2529-2536, 2009.

[31] D. K. Yadav, M. A. Quraishi, and B. Maiti, "Inhibition effect of some benzylidenes on mild steel in $1 \mathrm{M} \mathrm{HCl}$ : an experimental and theoretical correlation," Corrosion Science, vol. 55, pp. 254266, 2012.

[32] Z. Tao, S. Zhang, W. Li, and B. Hou, "Corrosion inhibition of mild steel in acidic solution by some oxo-triazole derivatives," Corrosion Science, vol. 51, no. 11, pp. 2588-2595, 2009.

[33] P. Singh, V. Srivastava, and M. A. Quraishi, "Novel quinoline derivatives as green corrosion inhibitors for mild steel in acidic medium: electrochemical, SEM, AFM, and XPS studies," Journal of Molecular Liquids, vol. 216, pp. 164-173, 2016.

[34] I. Ahamad, R. Prasad, and M. A. Quraishi, "Adsorption and inhibitive properties of some new Mannich bases of Isatin derivatives on corrosion of mild steel in acidic media," Corrosion Science, vol. 52, no. 4, pp. 1472-1481, 2010.

[35] Y. Tang, X. Yang, W. Yang, R. Wan, Y. Chen, and X. Yin, “A preliminary investigation of corrosion inhibition of mild steel in $0.5 \mathrm{M} \mathrm{H}_{2} \mathrm{SO}_{4}$ by 2-amino-5-(n-pyridyl)-1,3,4-thiadiazole: polarization, EIS and molecular dynamics simulations," Corrosion Science, vol. 52, no. 5, pp. 1801-1808, 2010.

[36] A. R. S. Priya, V. S. Muralidharan, and A. Subramania, "Development of novel acidizing inhibitors for carbon steel corrosion in $15 \%$ boiling hydrochloric acid," Corrosion, vol. 64, no. 6, pp. 541-552, 2008.

[37] C. Verma, M. A. Quraishi, E. E. Ebenso, I. B. Obot, and A. El Assyry, "3-amino alkylated indoles as corrosion inhibitors for mild steel in $1 \mathrm{M} \mathrm{HCl}$ : experimental and theoretical studies," Journal of Molecular Liquids, vol. 219, pp. 647-660, 2016.

[38] E. E. Elemike, D. C. Onwudiwe, H. U. Nwankwo, and E. C. Hosten, "Synthesis, crystal structure, electrochemical and anticorrosion studies of Schiff base derived from o-toluidine and ochlorobenzaldehyde," Journal of Molecular Structure, vol. 1136, pp. 253-262, 2017.

[39] R. Solmaz, E. Altunba, and G. Karda, "Adsorption and corrosion inhibition effect of 2-((5-mercapto-1,3,4- thiadiazol-2ylimino)methyl)phenol Schiff base on mild steel," Materials Chemistry and Physics, vol. 125, no. 3, pp. 796-801, 2011.

[40] X. Wang, Y. Wan, Y. Gu et al., "Inhibition and adsorptive behavior of synthesized 1, 4-bis (2-benzimidazolyl) benzene on mild steel in $3 \mathrm{~m}$ HCL solution," International Journal of Electrochemical Science, vol. 9, no. 4, pp. 1840-1853, 2014.

[41] K. Mallaiya, R. Subramaniam, S. S. Srikandan, S. Gowri, N. Rajasekaran, and A. Selvaraj, "Electrochemical characterization 
of the protective film formed by the unsymmetrical Schiff's base on the mild steel surface in acid media," Electrochimica Acta, vol. 56, no. 11, pp. 3857-3863, 2011.

[42] A. K. Singh and M. A. Quraishi, "Adsorption properties and inhibition of mild steel corrosion in hydrochloric acid solution by ceftobiprole," Journal of Applied Electrochemistry, vol. 41, no. 1, pp. 7-18, 2011.

[43] N. K. Gupta, M. A. Quraishi, C. Verma, and A. K. Mukherjee, "Green Schiff's bases as corrosion inhibitors for mild steel in 1 $\mathrm{M} \mathrm{HCl}$ solution: experimental and theoretical approach," RSC Advances, vol. 6, no. 104, pp. 102076-102087, 2016.

[44] K. R. Ansari, M. A. Quraishi, and A. Singh, "Corrosion inhibition of mild steel in hydrochloric acid by some pyridine derivatives: An experimental and quantum chemical study," Journal of Industrial and Engineering Chemistry, vol. 25, pp. 8998, 2015. 

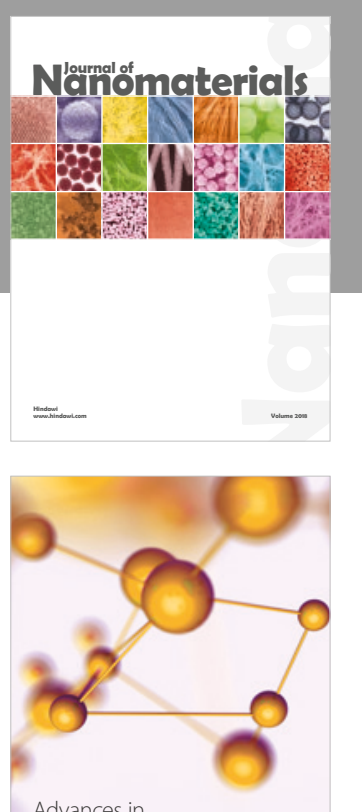

Physical Chemistry
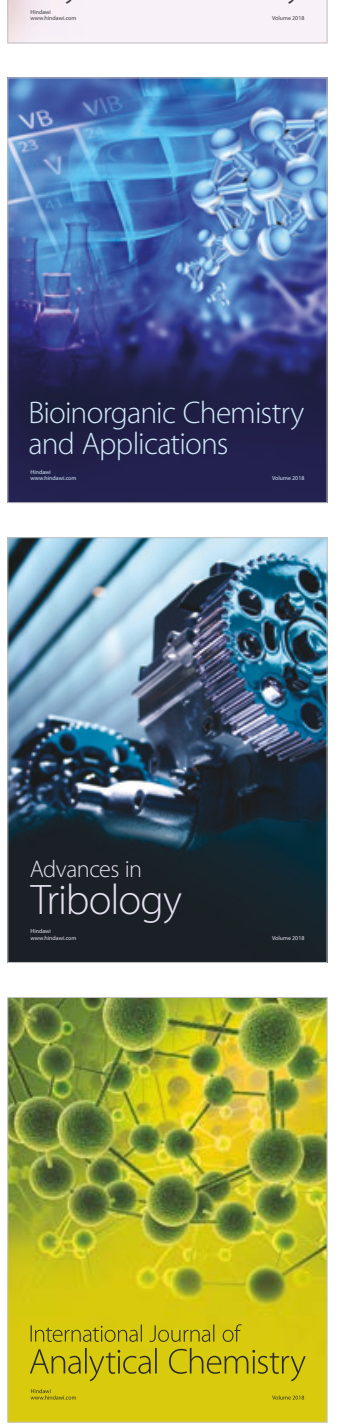

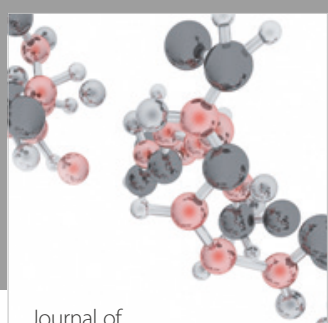

Analytical Methods

in Chemistry

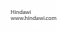

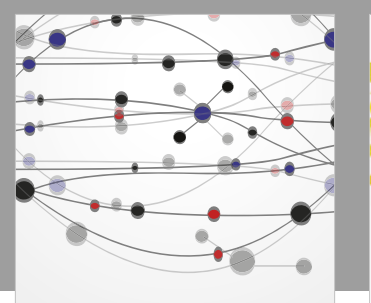

The Scientific World Journal

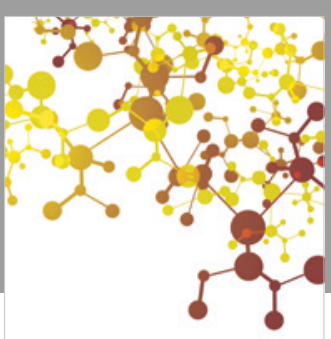

Journal of

Applied Chemistry
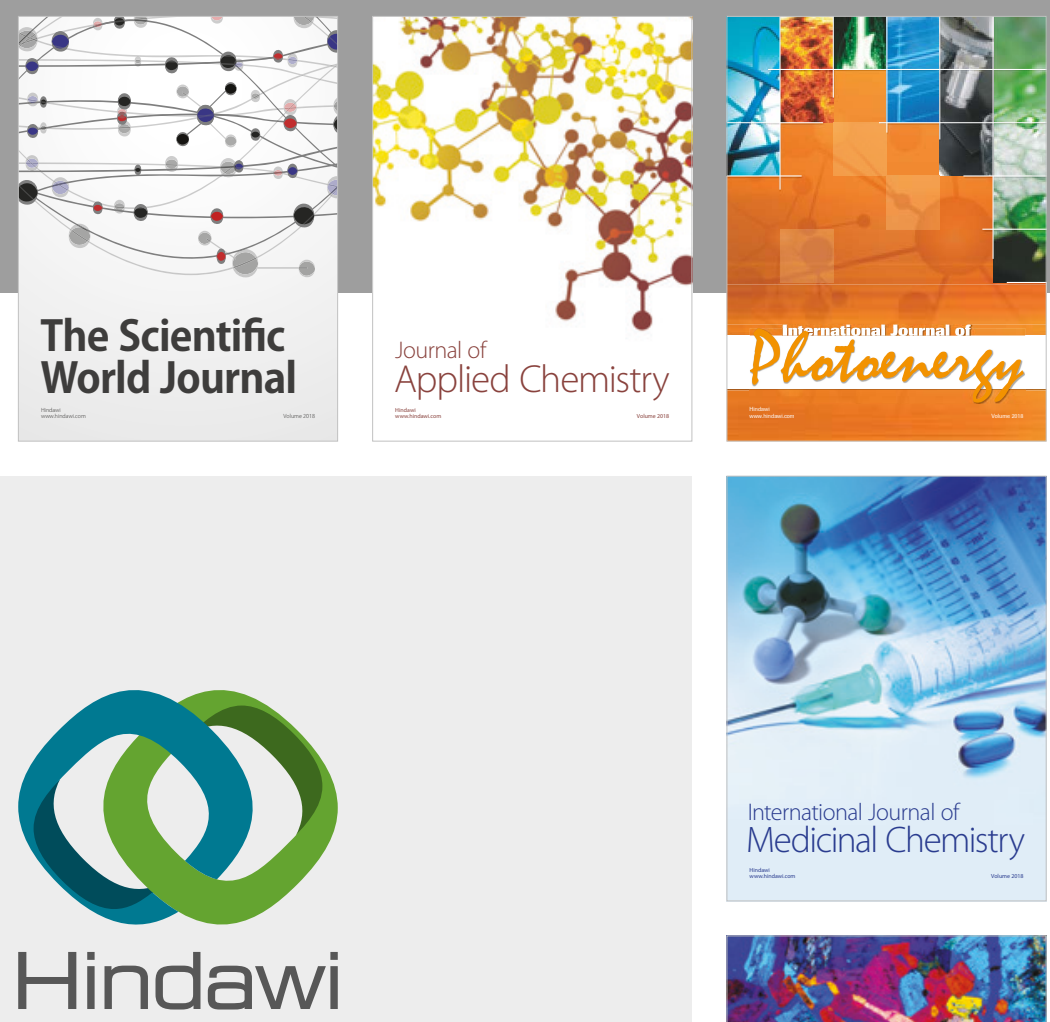

Submit your manuscripts at

www.hindawi.com
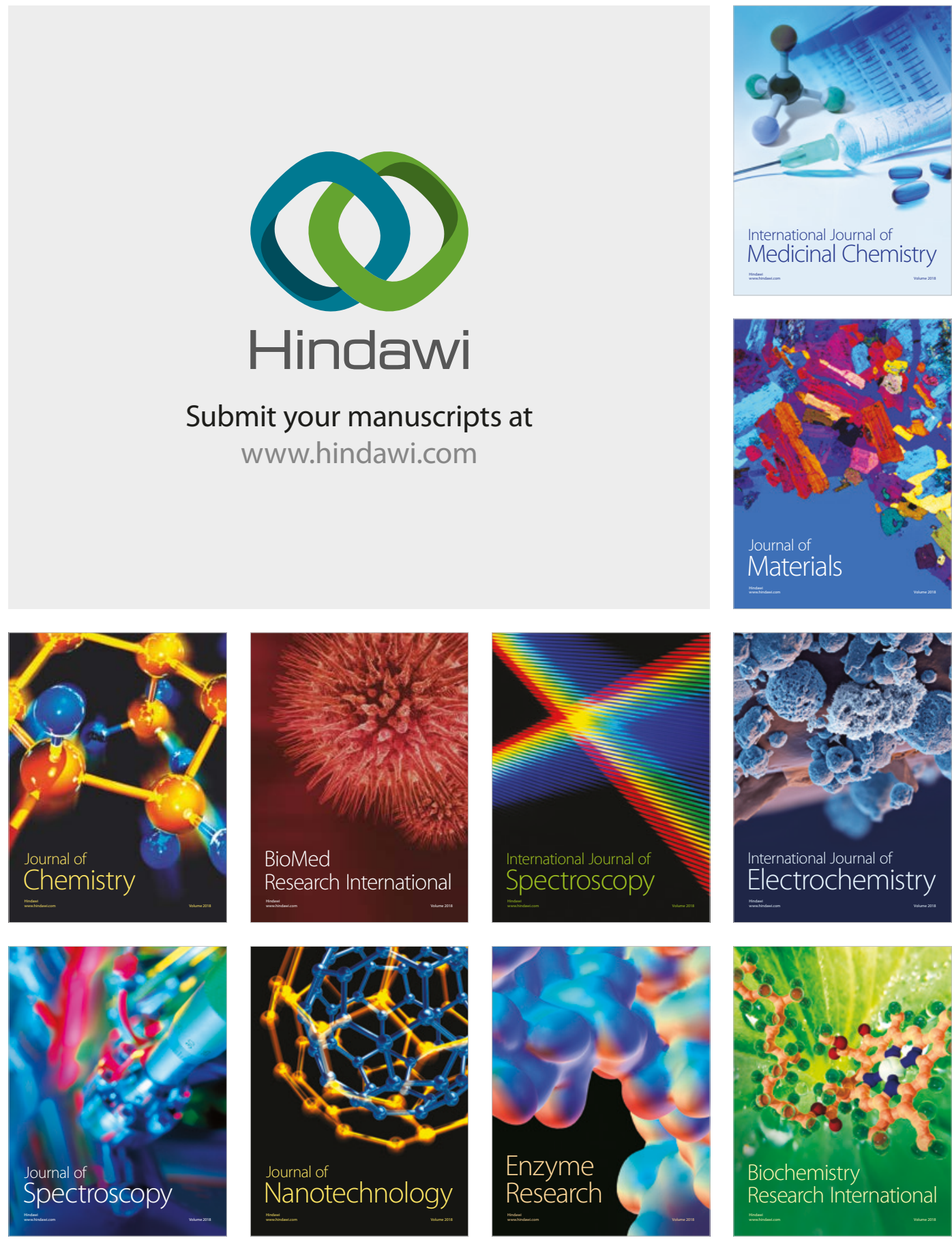
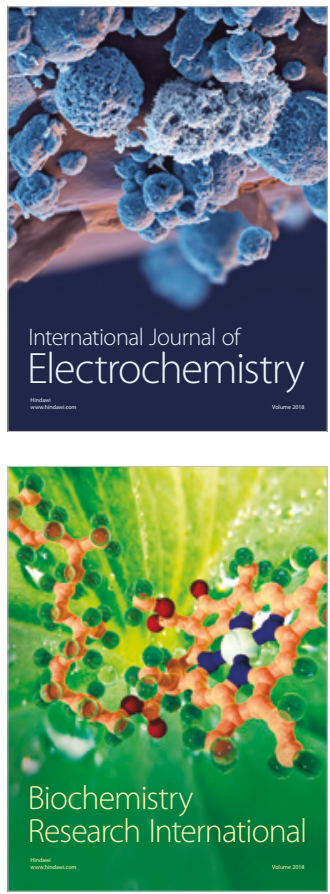